Document downloaded from:

http://hdl.handle.net/10251/145397

This paper must be cited as:

Olmeda, P.; Martín, J.; Novella Rosa, R.; Blanco-Cavero, D. (01-0). Assessing the optimum combustion under constrained conditions. International Journal of Engine Research. 21(5):811-823. https://doi.org/10.1177/1468087418814086

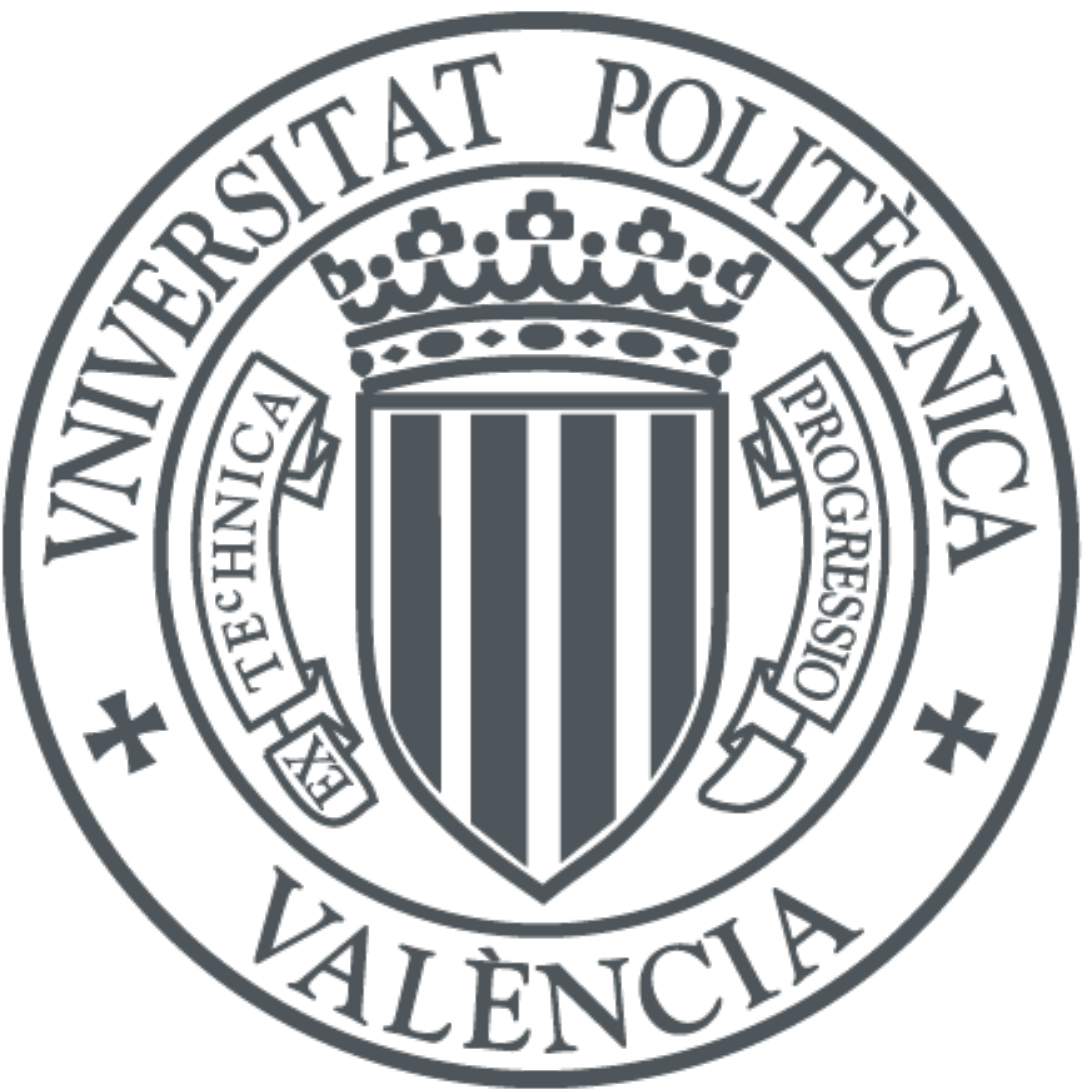

The final publication is available at

https://doi.org/10.1177/1468087418814086

Copyright SAGE Publications

Additional Information 


\title{
Assessing the optimum combustion under constrained conditions
}

\author{
Pablo Olmeda, Jaime Martín, Ricardo Novella and Diego Blanco-Cavero
}

\begin{abstract}
This work studies the optimum heat release law (HRL) of a DI diesel engine under constrained conditions. For this purpose, a OD predictive model of a diesel engine is coupled to an optimization tool used to shape the HRL in order to optimize some outputs (maximize gross indicated efficiency - GIE - and minimize $N O_{x}$ emissions) while keeping several restrictions (mechanical limits such as maximum peak pressure and maximum pressure rise rate). In a first step, this methodology is applied under different heat transfer (HT) scenarios without restrictions to evaluate the possible gain obtained through the thermal isolation of the combustion chamber. Results derived from this study show that HT has a negative effect on GIE ranging from $-4 \%$ of the fuel energy $\left(\dot{m}_{f} H_{v}\right)$, at high engine speed and load, up to $8 \% \dot{m}_{f} H_{v}$, at low engine speed and load. In a second step, different mechanical limits are applied resulting in a GIE worsening from $-1.4 \% \dot{m}_{f} H_{v}$ up to $-2.8 \% \dot{m}_{f} H_{v}$ compared to the previous step when nominal constraints are applied. In these conditions, a temperature swing coating that covers the piston top and cylinder head is considered obtaining a maximum GIE improvement of $+0.5 \% \dot{m}_{f} H_{v}$ at low load and engine speed. Finally, $N O_{x}$ emissions are also included in the optimization obtaining the expected tradeoff between GIE and $N O_{x}$. Under this optimization, cutting down the experimental emissions by $50 \%$ supposes a GIE penalty up to $-8 \% \dot{m}_{f} H_{v}$ when comparing to the optimum combustion under nominal limits, while maintaining the experimental GIE allows to reduce the experimental emissions $30 \%$ at high load and $65 \%$ at low load and engine speed.
\end{abstract}

\section{Keywords}

Diesel engine, Combustion optimization, $N O_{x}$ emissions, Temperature swing coating, Efficiency

\section{Abbreviations}

CMT-Motores Térmicos, Universitat Politècnica de València, Camino de Vera s/n, 46022, Valencia, Spain

Corresponding author:

Jaime Martín, CMT-Motores Térmicos, Universitat Politècnica de València, Camino de Vera s/n, 46022, Valencia, Spain

Email: jaimardi@mot.upv.es 


$\begin{array}{ll}\text { ATDC } & \text { After Top Dead Center } \\ \text { BMEP } & \text { Brake Mean Effective Pressure } \\ \text { CAD } & \text { Crank Angle Degrees } \\ \text { CR } & \text { Compression Ratio } \\ \text { DI } & \text { Direct Injection } \\ \text { EGR } & \text { Exhaust Gas Recirculation } \\ \text { GIE } & \text { Gross Indicated Efficiency } \\ \text { HRL } & \text { Heat Release Law } \\ \text { HRR } & \text { Heat Release Rate } \\ \text { HSDI } & \text { High Speed Direct Injection } \\ \text { HT } & \text { Heat Transfer } \\ H_{v} & \text { Lower Heating Value } \\ \text { ICE } & \text { Internal Combustion Engine } \\ \text { LNT } & \text { Lean } N O_{x} \text { trap } \\ \dot{m}_{f} & \text { Fuel mass flow rate } \\ \text { NEDC } & \text { New European Driving Cycle } \\ \text { NSGA } & \text { Non Sorted Genetic Algorithm } \\ \text { PEMS } & \text { Portable Emissions Measurement System } \\ \text { PCCI } & \text { Premixed Charge Compression Ignition } \\ \text { RDE } & \text { Real Driving Emissions } \\ \text { RCCI } & \text { Reactivity Controlled Compression Ignition } \\ \text { SCR } & \text { Selective Catalytic Reduction } \\ \text { SOC } & \text { Start of Combustion } \\ \text { TBC } & \text { Thermal Barrier Coating } \\ \text { TDC } & \text { Top Dead Center } \\ \text { WLTP } & \text { Worldwide harmonized Light vehicles Test Proce- } \\ & \text { dures } \\ & \end{array}$

\section{Acknowledgements}

This work was partially funded by GM Global R\&D and the Government of Spain through Project TRA2017-89894-R. In addition, the authors acknowledge that some equipment used in this work has been partially supported by FEDER project funds (FEDER-ICTS-2012-06), framed in the operational program of unique scientific and technical infrastructure of the Ministry of Science and Innovation of Spain. Diego Blanco-Cavero is partially supported through contract FPI-S2-2016-1356 of the Programa de Apoyo para la Investigacin y Desarrollo (PAID) of Universitat Politcnica de Valncia.

\section{Introduction}

Within the last two decades, the modern DI Diesel engine has proven to be an economical and attractive alternative in the modern passenger car segment. This is attributable to its higher process efficiency and torque characteristics. However, tests using Portable Emissions Measurement Systems (PEMS) have shown that diesel cars emit much more $N O_{x}$ on the road than during certification on the New European Driving Cycle (NEDC) [1], which has been the standard test procedure from Euro I until Euro VI. To tackle this issue, governments have imposed new tests procedures such as Worldwide harmonized Light vehicles Test Procedures (WLTP), in effect from September 2017, and Real Driving Emissions (RDE), in effect from September 2019 onwards, which are more representative of real driving conditions. This issue is leading OEMs to improve the existent or add new aftertreatment systems such us LNT or SCR, which permits to drastically cut down these emissions, giving room to another problem: $\mathrm{CO}_{2}$ limitation. According to EU legislation [2], the fleet average by all new cars will be limited to 95 grams of $\mathrm{CO}_{2}$ per kilometre in 2020, which means a fuel consumption of around $3.61 / 100 \mathrm{~km}$ for a diesel car and represents a reduction of $27 \%$ in comparison with 2015 target.

To meet this limitation, OEMs are developing new electric and hybrid vehicles to decrease the $\mathrm{CO}_{2}$ fleet average emissions but they also need to reduce fuel consumption from their ICE cars to reach this value. Focused in this last aim, some combustion concepts such as RCCI [3] and PCCI [4] or thermal insulation by means of temperature swing coatings $[5,6]$ are being investigated. In the thermal insulation approach, new materials, temperature of which can fluctuate following the transient gas temperature, are being developed. The higher temperature achieved during combustion and expansion strokes leads to a heat loss reduction that not only increases efficiency but also increases exhaust gas temperature, improving considerably the aftertreatment performance. Additionally, lower temperatures during the intake stroke contribute to higher volumetric efficiencies.

In this scenario, tools that explore the performance of such techniques are useful to know where the energy can be recovered. Some authors have used energy balances [7, 8] for identifying the paths followed by the chemical energy of fuel. This method allows assessing the potential efficiency improvements by recovering part of the thermal energy loss. Another interesting method is the application of the secondlaw of thermodynamics [9] to assess an exergy (available energy) balance taking into account irreversibility in engine processes. This second-law analysis provides a more critical and thorough insight into the engine processes by defining the term of availability destruction or irreversibility, pointing in this way the specific engine processes that could improve the engine performance.

However, none of these methods explore the maximum possible efficiency given by an ideal combustion taking into 
account all processes occurring in the combustion chamber. This efficiency limit establishes a boundary that can be used as a benchmark to compare different combustion strategies at given operating conditions. With this aim, various authors $[10,11,12]$ have studied the optimum shape of the Heat Release Law (HRL) imposing several constraints to pressure and $N O_{x}$ emissions. However, they use simple 0D models that do not take into account important phenomena such as the heat capacity change due to temperature and composition variations, deformations (volume change), injected fuel mass and blow-by leakages $([10,11]$ do consider mass trapped in the crevice volume). Skipping these processes has an effect in the determination of the optimum shape of HRL and it is important when assessing the efficiency of the cycle.

Based on that, in this work an optimization tool based on genetic algorithms has been coupled to an in-house developed 0D model which takes into account all phenomena involved in the combustion process in order to obtain the optimum HRR and the cycle efficiency under different constrained conditions. This approach has been applied to different operating conditions to get the combustion profile that maximizes the engine efficiency while keeping some mechanical and performing restrictions, such as peak pressure, pressure rise rate and $N O_{x}$ emissions. Additionally, the optimization has also been carried out in a scenario in which some combustion chamber walls are coated with a specific material called SiRPA reported by Wakisaka et al. [5], capable to change its surface temperature during the entire cycle trying to reproduce the gas transient temperature.

Thus, the main objectives of the present work are the following:

- To asses the best combustion evolution by computing the optimum HRL in terms of GIE and the penalties derived from the compliance of some mechanical limits.

- To evaluate the potential benefit of reducing the thermal limitation in realistic conditions by means of the application of a specific coating to cylinder-head and piston.

- To evaluate the effect of $N O_{x}$ emissions limitations in the optimum HRL and to analyse the trade-off between the best achievable GIE and $N O_{x}$ emissions.

\section{Experimental facility}

A 4-cylinder HSDI diesel engine calibrated under Euro4 regulation, main characteristics of which are presented in Table 1, was used for the calibration and validation of the models. The engine was controlled using a commercial controller system - DRIVVEN. This tool works as a conventional control unit and, additionally, it is able to acquire, analyse and record different instantaneous signals from the engine (e.g., in-cylinder pressure, intake and exhaust pressures, rail pressure and the current clamp signal corresponding to the injection command).

The engine was installed in a fully instrumented test cell to acquire the standard measurements necessary to perform the complete combustion diagnosis. To provide information for the lumped conductance model commissioning and validation, 88 thermocouples were installed at different locations of the engine block and cylinder-head. Furthermore, intake and exhaust conditions were measured in order to perform a detailed analysis of the in-cylinder conditions during both close and open cycle: air and fuel mass flows, gas temperatures and pressures at different intake and exhaust positions were recorded at low frequency $(10 \mathrm{~Hz})$ and then averaged.

As commented in the Introduction section, the RDE cycle will be used as a certification cycle from September 2019 onwards. This cycle will be the first one tested out of the laboratory environment and it basically covers the whole engine map. Figure 1 shows the full load curve of the multicylinder engine (black line) along with the engine map areas covered by different legislation (blue, grey and red lines) and the experimental operating conditions optimized in this work (green dots). As can be seen, both NEDC and WLTP cover a little portion of the low engine speed map, unlike the new RDE that forces OEMs to optimize the whole engine map.

As can be seen in Figure 1, the optimization methodology presented here has been applied to 7 operating conditions that represent the whole engine map in order to cover the total RDE area. This experimental matrix (main characteristics of which are presented in Table 2) includes 5 points at partial load and 2 additional characteristic points: maximum torque and maximum power points. These points will be named by using a composition of 2 numbers, the first one means the engine speed in revolutions per minute while the second one refers to the experimental bmep in bar (engine speed_bmep).

\section{Modelling tools}

\section{Description}

During the present study two different OD single-zone thermodynamic models (Calmec and SiCiclo) were used. Both of them share the same main hypothesis: 
- Chamber pressure and temperature are assumed to be spatially uniform.

- Three species (air, fuel vapor and stoichiometric combustion products) are considered [13].

- Ideal gas law is used to calculate gas mean temperature.

- A filling and emptying model is used to calculate the trapped mass [14].

- Specific heat of the gas depends on both temperature and composition [15].

- Instantaneous blow-by leakage is calculated with a model based on the isentropic nozzle flow [14].

- Chamber volume deformation is calculated by means of a simple deformation model [16].

- Heat transfer to the chamber walls is calculated with a modified Woschni-like model [17].

Besides, a lumped conductance model was used to calculate wall temperatures in the chamber and ports. It consists of 102 nodes in the cylinder head, 66 in the liner, 10 in the piston and some boundary nodes that take into account the oil, coolant, fresh air, in-cylinder gas, and intake and exhaust gases. More details of this model can be seen at [18].

On the one hand, Calmec is the combustion analysis tool that allows calculating the HRR from the instantaneous evolution of in-cylinder gas properties by solving the $1^{\text {st }}$ law of thermodynamics and modelling the internal energy terms based on the instantaneous pressure evolution. The model considers all relevant engine subsystems through the combination of both physical and semi-empirical submodels to calculate the heat transfer flow to combustion chamber walls and ports, split of mechanical losses and intake and exhaust processes [7]. This model was used to perform the combustion analysis in the experimental points.

On the other hand, SiCiclo [13] is a predictive tool that, using the HRL as main input, is able to calculate the pressure evolution with the purpose of predicting engine performance and fuel consumption or obtaining boundary conditions for specific combustion models with higher computational requirements $[19,20]$. This model is the core tool in the present study, where it has been coupled to an optimization tool, as it is explained in the Methodology section .

Since the energy term due to the fuel injection and vaporization is considered by the $0 \mathrm{D}$ model it is assumed that the fuel is injected in the chamber following the same rate that as the Heat Release Rate (HRR) but in the previous calculation step $\left(0.5^{\circ}\right)$. This means that the amount of fuel injected in a calculation step is burnt in the following step, which is $0.5^{\circ}$ later as explained previously.

Finally, a $N O_{x}$ model [21], which uses the evolution of thermodynamic variables to compute the production of $N O_{x}$ along the cycle, is coupled to SiCiclo. This model employs the HRL for tracking the $N O_{x}$ formation process through thermal mechanism estimating the flame temperature and, additionally, it considers $N O_{x}$ reduction through the re-burning process. It is important to remark that this model only takes into account $N O_{x}$ formation through thermal mechanism (with a correction for other formation mechanisms - see [21]), therefore, even though it is the most relevant in diesel engines, this assumption could lead to some errors in cycles with high premixed combustion fraction.

\section{Calibration and validation}

Both 0D models were adjusted to ensure the accurate estimation of the heat transfer to different engine parts, where special attention was paid to the heat rejection in the combustion chamber. Thus, an in-house methodology [22] was implemented to determine some experimental uncertainties related to in-cylinder pressure (pressure pegging and TDC position) along with some engine characteristics (dynamic and static compression ratios, deformation model constant and HT convective model adjustment). The adjustment method is based on the application of the first law of thermodynamics to motoring tests to obtain the HRR residuals (it should be zero because no fuel is injected). A multi-variable linear regression is used to find the values of the parameters by means of the least square method. More details of the process can be found in [22].

Geometry of the lumped conductance model [23] nodes was adjusted to fit the real engine geometry and to facilitate the comparison between experimental and modeled nodes temperatures (in the locations where thermocouples were installed at the cylinder-head and liner). Once the lumped model was built and included in the 0-D models, the experimental temperatures obtained with the thermocouples were used to validate the results provided by the lumped conductance model, obtaining a mean error about $5^{\circ} \mathrm{C}$ and a maximum error lower than $10^{\circ} \mathrm{C}$ in most cases [24].

Once calibrated, the validation of the $0 \mathrm{D}$ predictive model can be observed in Figure 2, where both experimental and modelled efficiencies of points covering the whole engine map are plotted. The mean error in all points is lower than $0.1 \%$ of the fuel energy $\left(\dot{m}_{f} H_{v}\right)$ when the experimental HRL is used. 
The $N O_{x}$ model was calibrated using 34 experimental points and it was validated over 100 points covering the whole range of engine map. Figure 3 shows the comparison between modelled and experimental $N O_{x}$ emissions in the validation tests, obtaining a mean error around $11 \%$. Moreover, taking into account that Arrègle et al. [25] indicates that a deviation of $\pm 1 \%$ in the trapped mass estimation leads to an error up to $\pm 30 \%$ in the $N O_{x}$ prediction, it can be concluded that the accuracy of the model is reasonably good.

\section{Methodology}

The main objective of this work is the optimization of the HRL to maximize GIE and minimize $N O_{x}$ emissions under different constrained conditions. To do that, a OD model has been coupled to an optimization tool that, using genetic algorithms, is able to obtain the best HRL that optimizes GIE, in the first two cases, and GIE along with $N O_{x}$ emissions in the last study. Figure 4 shows the information flow between the optimization tool and the models when performing the optimization. As can be seen, the optimization tool proposes a set of inputs that allows shaping the HRL, which is used by both OD and $N O_{x}$ models to perform the cycle calculation obtaining GIE and $N O_{x}$ emissions as main outputs. Then, the optimization tool receives these results as feedback and proposes a new set of inputs as a function of the fitness of the previous ones.

The combustion parametrization has been done by splitting the HRR in 8 sectors in which the optimization tool is able to modify the duration (in ${ }^{\circ}$ ) and the HRR value (non dimensional), resulting in 16 inputs. Each iteration the tool proposes a set of inputs and the HRR is constructed interpolating these values. Prior to the OD model execution, this shaped HRR is scaled in order to have a cumulated heat release that coincides with the fuel energy. Then, the thermodynamic cycle and $N O_{x}$ emissions are computed using the resultant HRL and these outputs along with additional ones such as the peak pressure and the maximum pressure rise rate in the cycle are provided to the optimization tool, that evaluates the fitness of the iteration. After that, the optimization tool checks if any limit is trespassed (in case any limit had been imposed), and in this case the HRL is discarded, proposing a new iteration.

The algorithm needs an initial number of inputs combinations (initial population), which are created following a Sobol algorithm [26] (Monte Carlo numerical method) that generates samples to fill the design space in a uniform way. After this initial population is evaluated, the tool proposes a new generation based on a Non-dominated Sorting Genetic Algorithm for Multi-Objective Optimization (NSGA-II) [27], an evolutionary algorithm that uses two operators for generating new designs: cross-over and mutation. Cross-over consists in two designs of the parent generation exchanging their genetic material to form a new design in the next generation while mutation randomly modifies the genetic material of a design to create a new design in the next generation. The objectives of these two operators are to obtain individuals with better characteristics than the parents and to inhibit the premature convergence in local maximum/minimum. More details of this algorithm can be found in [27]

Once the optimization methodology has been explained, the Results section is structured as follows:

- The optimum HRR is calculated in all studied points with and without heat transfer and without considering pressure limits. This step assesses the change of optimum HRL shape and GIE due to the effect of heat transfer.

- Then, the effect of different pressure limits (peak pressure and pressure rise rate) is assessed on the optimum HRL and GIE. This step provides a more realistic combustion since experimental operating conditions are also limited by these constraints.

- A temperature swing coating is applied to the piston top and cylinder head surfaces in the 0D model under nominal constraints, thus providing the best achievable cycles under this insulated scenario, more realistic than adiabatic conditions explored in the first step.

- Finally, $N O_{x}$ emissions are also considered in the optimization study obtaining a trade-off between efficiency and $N O_{x}$. The HRL shapes obtained in this subsection are directly comparable to the experimental ones.

\section{Results and discussion}

As known, maximum efficiency of an ICE is given by Otto cycle, whose main characteristic is a constant volume combustion occurring in the TDC. As shown in equation 1 and, taking into account that theoretical cycles use air with constant properties (perfect gas) along the cycle evolution $(\gamma=1.4)$, its efficiency is only function of the engine compression ratio $(\mathrm{CR})$ :

$$
\eta_{\text {Otto }}=\left(1-\frac{1}{C R^{\gamma-1}}\right) 100
$$


Since the compression ratio of the studied engine is 17.5 , the resultant Otto efficiency in this case is $68.2 \%$. This value provides the efficiency ceiling in this engine independently of the operating conditions. However, this ideal cycle is far from a real one due to the assumption of the following hypothesis:

- No leakages are considered.

- Heat addition corresponds to a complete combustion

- There is no losses due to heat rejection.

- There is no exhaust losses.

- Processes are reversible.

- The trapping air process is substituted by a heat transfer process at constant volume.

The assumption of these hypothesis leads to an efficiency much higher than if the highest efficiency combustion is obtained considering real conditions. In this section, the maximum efficiency cycles are assessed under real conditions at different engine operating conditions and under different scenarios, taking into account all phenomena described in the Modelling tools section.

\section{Optimum HRL without constraints}

This subsection studies the optimum HRL of the selected points when no constraints are considered. Additionally, this study has also been performed considering an adiabatic engine to assess the change in the optimum combustion due to heat transfer. Figure 5 shows the results of this initial optimization performed at 1500_3 and at 3500_19. These points have been chosen to compare two extreme operating conditions, since the behaviour of the HRL at intermediate points was similar. As can be seen, adiabatic combustions developed instantaneously ( 0.5 is the minimum allowed by the calculation step) and the Start of Combustion (SOC) obtained at 1500_3 and 3500_19 was $1.5^{\circ}$ ATDC and $1^{\circ}$ ATDC while the GIE reached was $53.2 \%$ and $54.5 \%$ respectively. These slightly delayed combustions with respect to Otto cycle are due to the consideration of real processes such as blow-by, combustion chamber, deformation and change of heat capacity due to composition and temperature variations (unlike the ideal cycle that does not take them into account).

When heat transfer was considered, combustion was delayed but its duration was maintained instantaneous. SOCs of 1500_3 and 3500_19 were delayed $6.5^{\circ}$ and $3^{\circ}$ respectively resulting in an efficiency loss of $-8.2 \% \dot{m}_{f} H_{v}$ and $-3.7 \% \dot{m}_{f} H_{v}$ respect to the adiabatic case. As can be seen, heat transfer is more important at low engine speed and load leading to a more delayed optimum combustion and a higher efficiency loss.

Figure 6 shows the GIE variation respect to adiabatic unconstrained conditions when considering HT in the engine map. The two cases presented in Figure 5 corresponded to the extreme conditions of load and engine speed, thus a monotonous behaviour can be appreciated in intermediate points.

As a conclusion of this subsection, it can be confirmed that the optimum combustion develops as fast as it is allowed to. If no constraints are considered its duration is instantaneous, as Otto cycle, but its SOC is delayed respect to TDC and its efficiency is not as high due to the consideration of different real phenomena such as blow-by leakage, deformation, real gas properties and fuel vaporization. Additionally, HT consideration produced a delay in the optimum HRL and it had an important effect on GIE ranging from $-8 \% \dot{m}_{f} H_{v}$ at low load and engine speed to $-4 \% \dot{m}_{f} H_{v}$ at high load and engine speed.

\section{Optimum HRL with pressure constraints}

In this subsection, the optimum HRL has been studied when two different pressure constraints are considered. The first limit is the pressure rise rate (PRR), which is related to combustion noise, while the second one is the peak pressure (PP), value of which is limited by OEMs to avoid mechanical problems. In the studied engine, its constructor set a PRR limit of $10 \mathrm{bar} /{ }^{\circ}$ and a maximum pressure of $160 \mathrm{bar}$ to keep the engine integrity. However, current innovative engine design and materials allow overcoming these limits leading to engine blocks able to cope with maximum pressures up to 210 bar [28]. For this reason, the study does not only focus on the nominal limits of this engine but also in other plausible boundaries.

First of all, different PRR limits were applied to the optimization study at 3500_19, obtaining the results plotted in Figure 7 where also the unconstrained solution is shown. For the sake of brevity, this point will be the only one plotted here since the optimum combustions in the rest of the points followed the same behaviour. As can be seen, the optimum HRL is shaped in a way to exactly reproduce the pressure evolution marked by the PRR limit considered. Combustion duration increased and SOC advanced as limit became more restrictive, thus keeping the combustion centre not so far from TDC.

Plots of Figure 8 show the GIE variation when considering different PRR limits (2.5 bar $/{ }^{\circ}$ at left and $10 \mathrm{bar} /{ }^{\circ}$ at right) in the engine map. As can be seen, at low load the effect of both limits is similar leading to an efficiency loss of $-1.4 \% \dot{m}_{f} H_{v}$ 
while at high load the most tightened PRR scenario decreases efficiency $-2.8 \% \dot{m}_{f} H_{v}$ unlike the most relaxed one, where the efficiency loss is lower $\left(-1.8 \% \dot{m}_{f} H_{v}\right)$.

On the other hand, when different peak pressure limits were applied to the unconstrained solution, Figure 9 was obtained. As shown, the optimum HRL with PP constraints is divided into two stages: the first one is an instantaneous combustion up to the limited pressure is reached and the second one consists on the heat release necessary to maintain this pressure constant until the total amount of fuel is burned. When limit is tightened, SOC of the optimum HRR advances and the duration of the combustion at constant pressure increases.

Plots of Figure 10 shows GIE variation when considering different PP limits (160 bar at left and 220 bar at right) in the engine map. First of all, GIE at low load is not affected since peak pressure in the optimum unconstrained solution in this region did not reach the imposed peak pressure limits. The efficiency loss due to the consideration of this PP limits increases monotonously with load, reaching $-2.5 \% \dot{m}_{f} H_{v}$ in the most constrained scenario and around $-1 \% \dot{m}_{f} H_{v}$ in the most relaxed one.

Finally, Figure 11 shows the evolution of pressure and HRL at 3500_19 when both pressure limits were considered in three scenarios: the first one represents the most constrained situation $\left(\mathrm{PRR}=2.5 \mathrm{bar} /{ }^{\circ}\right.$ and $\mathrm{PP}=160 \mathrm{bar}$ ), the second one indicates the most relaxed one $\left(\mathrm{PRR}=15 \mathrm{bar} /{ }^{\circ}\right.$ and $\mathrm{PP}=220$ bar) while the third one stands for the nominal limits of the engine ( $\mathrm{PRR}=10$ bar/ ${ }^{\circ}$ and $\mathrm{PP}=160$ bar). Additionally, the experimental evolution and the optimum unconstrained solution have also been included in this graph to compare them with the optimum limited solutions. In this graph, it can be seen that the optimum constrained combustion follows exactly the limits imposed leading again to a two-stage combustion, where the first stage is defined by the imposed PRR until the limited peak pressure is achieved and then, the HRL is shaped to maintain constant this maximum pressure until the total available energy is released. If the experimental combustion is compared with the constrained solution under nominal limits, it can be seen that the experimental one is much longer and its maximum pressure gradient and peak pressure are lower than the theoretical one.

Figure 12 shows the GIE variation when considering nominal pressure limits $\left(\mathrm{PRR}=10 \mathrm{bar} /{ }^{\circ}\right.$ and $\left.\mathrm{PP}=160 \mathrm{bar}\right)$ in the engine map if it is compared with the non constrained scenario. It can be seen that this efficiency loss is mainly dependant on load except at low engine speed and high load where it can also be discerned a dependency on engine speed because the peak pressure limit was not reached at this region. In any case, the reduction of GIE due to the consideration of nominal limits ranges from $-1.4 \% \dot{m}_{f} H_{v}$ at low load to $-2.8 \% \dot{m}_{f} H_{v}$ at high load and engine speed.

The conclusion stated in the previous subsection is also valid in this one, the optimum combustion develops as fast as it is allowed to. In this case, when pressure limits were taken into account, the optimum HRL was shaped in a way to reproduce exactly the considered constraints. GIE evolution under nominal pressure limits was plotted in Figure 13, where it can be seen an almost linear increase with load and engine speed starting from $44 \%$ and reaching GIE above $48 \%$ at the high load and engine speed region. This efficiency map establishes the maximum GIE achievable in the studied engine taking into account heat transfer and real pressure limits and it sets up the basis for the following studies.

\section{Temperature swing insulation scenario}

In order to asses the efficiency limits under a realistic thermal insulation scenario, unlike the ideal adiabatic one presented previously, the GIE variation experimented when applying a TBC on combustion chamber walls was assessed. Thus, the HRL was optimized here assuming that some combustion chamber walls were coated with $100 \mu \mathrm{m}$ of a previously reported material named as "silica-reinforced porous anodized aluminium" (SiRPA) [5] under nominal pressure limits. This material is capable to quickly change its surface temperature during the entire cycle following the gas transient temperature due to the its low volumetric specific heat capacity $\left(1300 \mathrm{~kJ} / \mathrm{m}^{3} \mathrm{~K}\right)$, half the one of solid aluminium, and thanks to its low thermal conductivity $(0.67$ $\mathrm{W} / \mathrm{mK}$ ). These properties permit that its temperature swings along the combustion cycle, reducing the temperature drop between gas and walls with the consequent lower heat rejection, higher efficiency and enhancement of exhaust gas temperatures. Additionally, lower temperatures during the intake stroke contribute to higher volumetric efficiencies. However, since this study is focused on thermal efficiency in closed cycle, only the effects of this coating on GIE are assessed. It is considered that only cylinder head and piston top surface are suitable for this coating, being not possible to apply it on the cylinder liner because of the friction with piston rings.

Figure 14 shows the temperature of the different combustion chamber walls and the gas mean temperature along the cycle with and without coating at 1500_3, which was the most benefited point when conducting this approach due to its higher heat rejection. As can be seen, the coating allows a temperature swing of around $60 \mathrm{~K}$ in the surfaces 
where coating was applied. Since this variation is much lower than the change of gas mean temperature along the cycle (20 times lower in this case), the effect produced in the optimum combustion is limited, and thus only a $0.5^{\circ}$ earlier combustion when coating is applied can be appreciated in the gas temperature rise in Figure 14. The variation of surface temperature along the cycle depends on the operating conditions, reaching $200 \mathrm{~K}$ at low engine speed and high load, but in no case this variation supposes more than $10 \%$ of the gas mean temperature change and its influence on the optimum combustion is reduced to a slightly earlier combustion as explained.

Figure 15 shows the effect of the coating on GIE in the engine map. As can be observed, points at low load and low engine speed are the most benefited ones when this approach is followed due to its higher heat transfer. However, the maximum benefit obtained due to the use of this coating does not reach $+0.5 \% \dot{m}_{f} H_{v}$ in this zone and it is around $+0.25 \%$ $\dot{m}_{f} H_{v}$ at the high load and engine speed zone.

Once the effect of coating on GIE has been assessed, the analysis continues in the next subsection with additional limitations due to pollutants and coming back to conventional wall properties. As explained, the maximum potential benefit of coating on GIE is lower than $+0.5 \%$ $\dot{m}_{f} H_{v}$. Since the consideration of $N O_{x}$ limits in next subsection will lead to combustion at lower temperatures, the coating effect would be even lower, thus this strategy is not considered in there.

\section{Optimum HRL with nominal constraints and $\mathrm{NO}_{x}$ model}

In this subsection $N O_{x}$ emissions were also included in the optimization methodology under nominal constraints $\left(\mathrm{PP}=160 \mathrm{bar}\right.$ and $\left.\mathrm{PRR}=10 \mathrm{bar}^{\circ}\right)$. Unlike previous analysis in which there was just one objective (GIE), including $N O_{x}$ emissions in the assessment leads to a multiobjective optimization problem with infinite solutions depending on the weight of each objective, thus resulting in a trade-off between efficiency and $N O_{x}$ emissions.

As extracted from previous subsections, the optimum combustion in terms of GIE was the fastest achievable one taking into account the imposed limits. Additionally, it is well-known that high temperature combustions enhance $N O_{x}$ formation. Thus, optimum solutions when GIE and $N O_{x}$ emissions are considered should be rapid combustions at low temperature. Evolution of mean gas temperature and HRL at some specific $N O_{x}$ emissions levels along with the optimum constrained solution under nominal limits and the experimental results are plotted in Figure 16 at 3500_19. For the sake of brevity, evolution of optimum HRL and pressures in all points are not shown but their behaviour are pretty similar to the ones plotted at this point. Main changes when $N O_{x}$ was forced to be reduced were that SOC was delayed and the first part of the combustion developed slower, however the total combustion duration did not vary significantly (it was always around $20^{\circ}$ in this point) because the second combustion stage was accelerated in order to increase GIE. As explained, optimum combustions developed fastly but delayed from TDC as $N O_{x}$ constraint became tighter to avoid high gas temperatures. This 2-stage combustion became even more differentiated as $N O_{x}$ was reduced, the first one became slower while the second one increased progressively its velocity.

In the top plot of Figure 17 the red line represents the best solutions in terms of maximum GIE and minimum $N O_{x}$ emissions obtained after the heat release optimization (red dots) at 3500_19. Additionally, other points of interest are also plotted there: green point stands for the experimental measurement, blue point represents the constrained optimum solution without $N O_{x}$ limits and greyscale points correspond to greyscale lines represented in Figure 16. As can be seen, the optimization methodology has improved the experimental GIE and specific $N O_{x}$ emissions, achieving an improvement of $+3 \% \dot{m}_{f} H_{v}$ in GIE if the experimental $N O_{x}$ emissions $(4.13 \mathrm{~g} / \mathrm{kWh})$ are maintained and a reduction of $1.5 \mathrm{~g} / \mathrm{kWh}$ in $N O_{x}$ if the experimental GIE $(44.1 \%)$ is kept constant. If the optimum trade off between GIE and $N O_{x}$ is analysed, it can be observed that a maximum GIE of $47.9 \%$ is achieved when no $N O_{x}$ emissions are taken into account (resultant from previous optimization) while the minimum $N O_{x}$ emissions are 1.64 $\mathrm{g} / \mathrm{kWh}$ with a penalty in GIE, which is reduced to $36.6 \%$. In any case, since the medium zone of the tradeoff with efficiencies higher than $44 \%$ and $N O_{x}$ emissions below 4 $\mathrm{g} / \mathrm{kWh}$ should be the target zone, three of the greyscale points located in this area will be later analysed. It is important to remark that this operating condition is the maximum power point in the engine map, so emissions ranging from $2 \mathrm{~g} / \mathrm{kWh}$ to $5 \mathrm{~g} / \mathrm{kWh}$ can be considered as normal.

The bottom plot of Figure 17 shows the GIE and $N O_{x}$ emissions optimization in all the studied points along with their experimental values. As can be seen, all tradeoffs improved clearly the experimental measurement, ranging from $1 \mathrm{~g} / \mathrm{kWh}$ to $5 \mathrm{~g} / \mathrm{kWh}$ of $N O_{x}$ emissions and GIE from $34 \%$ to $48 \%$ covering a wide range of optimum solutions. The only one tradeoff out of these ranges is 1500_3, $N O_{x}$ emissions of which are 10 times lower and GIE $-4 \% \dot{m}_{f} H_{v}$ 
lower than the other points, due to the use of $35 \%$ of EGR. These results are coherent with the experimental measurement, which is also in the same range, validating in this way the obtained tradeoff.

If these optimized tradeoffs were compared with the optimum cycle without $N O_{x}$ constraints or with the experimental points, several conclusions could be extracted. On the one hand, the first study is aimed to compare the $N O_{x}$ emissions levels of both theoretical optimization and experimental cases. However, since in some cases experimental emissions were higher than the worst case of the optimization, it was decided to compare them at $50 \%$ of the experimental $N O_{x}$ value. Thus, Figure 18 represents GIE variation of emitting $50 \%$ of experimental $N O_{x}$ in the engine map when comparing to the optimum combustion under nominal limits of PP and PRR. As can be seen, meeting these emissions targets supposes a GIE decrease that ranges from $-1 \% \dot{m}_{f} H_{v}$ at low load and engine speed to $-8 \% \dot{m}_{f} H_{v}$ at high load.

On the other hand, Figure 19 shows the variation of $N O_{x}$ emissions in relative value respect to the experimental case if experimental GIE of each studied point is assumed in the theoretical optimization. As can be observed, at low load and engine speed the optimization allows a reduction of $65 \%$ in $N O_{x}$ emissions if the experimental GIE is maintained, while at high load a decrease of $30 \%$ is achieved at the same GIE.

\section{Conclusions}

In this work, it has been analysed the optimum HRL in terms of GIE under different scenarios using a detailed OD predictive model that includes all relevant phenomena such as fuel vaporization, blow by leakages, combustion chamber deformation and real gas properties. The optimization has been performed under different scenarios defined by the consideration of some constraints such as maximum peak pressure or maximum pressure rise rate and the assessment of heat transfer, considering an adiabatic engine or a temperature swing coating applied to piston top and cylinder head. Finally, $N O_{x}$ emissions have also been included in the optimization process obtaining tradeoffs between GIE and $N O_{x}$ in all studied points. Main conclusions of the work are the following:

- Unconstrained optimum HRL with adiabatic chamber assumption was an instantaneous combustion starting around $1^{\circ}$ ATDC with GIE ranging from $52 \%$ to $55.5 \%$ depending on the operating point. These instantaneous combustions were not placed in the TDC due to the consideration of real processes such as blow-by, combustion chamber deformation and heat capacity change due to composition and temperature variations (unlike Otto cycle that does not take them into account).

- Heat transfer assessment under no constraints delayed the optimum HRL but it continued being an instantaneous combustion. GIE decreased from $-4 \%$ $\dot{m}_{f} H_{v}$ at high load and engine speed to $-8 \% \dot{m}_{f} H_{v}$ at low load and engine speed when nominal HT was considered.

- Optimum HRL when peak pressure and/or pressure rise rate limits were considered was divided into two stages: the first one burnt as quick as it was allowed (instantaneously if no PRR limit was applied or following the imposed pressure gradient if a PRR limit was considered) until the maximum pressure was reached, then the HRL was shaped to exactly obtain the maximum pressure marked by the limit until the total amount of fuel was burnt. The scenario where nominal limits $\left(\mathrm{PRR}=10 \mathrm{bar} /{ }^{\circ}\right.$ and $\left.\mathrm{PP}=160 \mathrm{bar}\right)$ were applied to the studied points led to an efficiency reduction ranging from $-1.4 \% \dot{m}_{f} H_{v}$ at low load to $-2.8 \% \dot{m}_{f} H_{v}$ at high load when comparing to the previous non restricted optimum solutions.

- The application of a temperature swing coating to the piston top surface and cylinder head walls did not have a big impact on optimum HRL, and made that optimum combustions started slightly earlier. These changes were translated to a marginal GIE increase ranging from less than $+0.5 \% \dot{m}_{f} H_{v}$ at low load and engine speed to $+0.25 \% \dot{m}_{f} H_{v}$ at high load and engine speed.

- The consideration of $N O_{x}$ emissions in the optimization problem led to a non unique optimum solution, but a set of optimum HRL that maximized GIE while minimizing $N O_{x}$ emitted. This group of solutions formed the expected tradeoff between these 2 variables, conditioning the final choice to the requirements of the specific operating condition. In any case, it have seen that decreasing $N O_{x}$ emissions until $50 \%$ of the experimental value implied a penalization on GIE up to $-8 \% \dot{m}_{f} H_{v}$ at high load when comparing to the optimum combustion under nominal limits of PP and PRR. Additionally, if the experimental GIE of each point is maintained in the optimum theoretical tradeoff, a decrease ranging from $30 \%$ at high load to $65 \%$ at low load in $N O_{x}$ emissions was achieved when comparing with the experimental emissions. 


\section{References}

1. Degraeuwe B and Weiss M. Does the New European Driving Cycle (NEDC) really fail to capture the NOX emissions of diesel cars in Europe? Environmental Pollution 2017; 222(X): 234-241. DOI:10.1016/j. envpol.2016.12.050.

2. The European Parliament and the Council of the European Union. REGULATION (EU) No 333/2014 OF the European Parliament and of the Council of 11 March 2014 amending Regulation (EC) No 443/2009 to define the modalities for reaching the 2020 target to reduce $\mathrm{CO} 2$ emissions from new passenger cars. Official Journal of the European Union 2014; 103(333): 15-21.

3. Benajes J, García A, Monsalve-serrano J et al. Exploring the limits of the reactivity controlled compression ignition combustion concept in a light-duty diesel engine and the influence of the direct-injected fuel properties. Energy Conversion and Management 2018; 157(December 2017): 277-287. DOI:10.1016/j. enconman.2017.12.028.

4. Kiplimo R, Tomita E, Kawahara N et al. Effects of spray impingement, injection parameters, and EGR on the combustion and emission characteristics of a PCCI diesel engine. Applied Thermal Engineering 2012; 37: 165-175. DOI:10.1016/j.applthermaleng.2011.11.011.

5. Wakisaka Y, Inayoshi M, Fukui K et al. Reduction of Heat Loss and Improvement of Thermal Efficiency by Application of Temperature Swing Insulation to DirectInjection Diesel Engines. SAE Int J Engines 2016; DOI: 10.4271/2016-01-0661.

6. Caputo S, Millo F, Torino $\mathrm{P}$ et al. Numerical Investigation on the Effects of Different Thermal Insulation Strategies for a Passenger Car Diesel Engine. SAE Int J Engines 2018; : 2154-2165DOI:10.4271/ 2017-24-0021.

7. Payri F, Olmeda P, Martín J et al. A New Tool to Perform Global Energy Balances in DI Diesel Engines. SAE Int J Engines 2014; DOI:10.4271/2014-01-0665.

8. Benajes J, Olmeda P, Martín J et al. Evaluation of swirl effect on the Global Energy Balance of a HSDI Diesel engine. Energy 2017; 122: 168-181. DOI: 10.1016/j.energy.2017.01.082.

9. Rakopoulos C and Giakoumis E. Second-law analyses applied to internal combustion engines operation.
Progress in Energy and Combustion Science 2006; 32(1): 2-47. DOI:10.1016/j.pecs.2005.10.001.

10. Eriksson L and Sivertsson M. Computing Optimal Heat Release Rates in Combustion Engines. SAE International Journal of Engines 2015; 8(3): 2015-010882. DOI:10.4271/2015-01-0882.

11. Eriksson L and Sivertsson M. Calculation of Optimal Heat Release Rates under Constrained Conditions. SAE Int J Engines 2016; DOI:10.4271/2016-01-0812.

12. Guardiola C, Climent H, Pla B et al. Optimal Control as a method for Diesel engine efficiency assessment including pressure and NOx constraints. Applied Thermal Engineering 2017; 117: 452-461.

13. Payri F, Olmeda P, Martín J et al. A complete OD thermodynamic predictive model for direct injection diesel engines. Applied Energy 2011; 88: 4632-4641. DOI:10.1016/j.apenergy.2011.06.005.

14. Payri F, Galindo J, Martín J et al. A Simple Model for Predicting the Trapped Mass in a DI Diesel Engine. SAE Technical Paper 2007-01-0494 2007; DOI:10.1016/ j.applthermaleng.2005.10.021.

15. Lapuerta M, Armas O and Hernández JJ. Diagnosis of DI Diesel combustion from in-cylinder pressure signal by estimation of mean thermodynamic properties of the gas. Applied Thermal Engineering 1999; c: 513-529.

16. Payri F, Molina S, Martín J et al. Influence of measurement errors and estimated parameters on combustion diagnosis. Applied Thermal Engineering 2006; 26(2-3): 226-236. DOI:10.1016/j.applthermaleng.2005.05.006.

17. Payri F, Margot X, Gil A et al. Computational Study of Heat Transfer to the Walls of a DI Diesel Engine. SAE Technical paper 2005-01-0210 2005; DOI:10.4271/ 2005-01-0210.

18. Torregrosa AJ, Olmeda P, Martín J et al. A Tool for Predicting the Thermal Performance of a Diesel Engine. Heat Transfer Engineering 2011; 32(10): 891904. DOI:10.1080/01457632.2011.548639.

19. Benajes J, Novella R, De Lima D et al. Analysis of combustion concepts in a newly designed two-stroke high-speed direct injection compression ignition engine. International Journal of Engine Research 2015; 16(1, SI): 52-67. DOI: $\{10.1177 / 1468087414562867\}$. 
20. Benajes J, Martín J, Novella R et al. Understanding the performance of the multiple injection gasoline partially premixed combustion concept implemented in a 2Stroke high speed direct injection compression ignition engine. Applied Energy 2016; 161: 465-475. DOI: $\{10.1016 /$ j.apenergy.2015.10.034\}.

21. Guardiola C, Martín J, Pla B et al. Cycle by cycle NOx model for diesel engine control. Applied Thermal Engineering 2017; 110: 1011-1020. DOI:10.1016/j. applthermaleng.2016.08.170.

22. Benajes J, Olmeda P, Martín J et al. A new methodology for uncertainties characterization in combustion diagnosis and thermodynamic modelling. Applied Thermal Engineering 2014; 71: 389-399. DOI:10.1016/j. applthermaleng.2014.07.010.

23. Torregrosa A, Olmeda P, Degraeuwe B et al. A concise wall temperature model for DI Diesel engines. Applied Thermal Engineering 2006; 26(11-12): 13201327. DOI:10.1016/j.applthermaleng.2005.10.021.

24. Broatch A, Olmeda P, García A et al. Impact of swirl on in-cylinder heat transfer in a light-duty diesel engine. Energy 2017; 119: 1010-1023. DOI:10.1016/j.energy. 2016.11.040.

25. Arrègle J, López JJ, Guardiola C et al. On Board NOx Prediction in Diesel Engines: A Physical Approach. Lecture Notes in Control and Information Sciences, Springer, London 2010; 402. DOI:https://doi.org/10. 1007/978-1-84996-071-7\_2.

26. Sobol IM. Monte carlo numerical methods, 1973.

27. Deb K, Agrawal S, Pratap A et al. A Fast Elitist Non-Dominated Sorting Genetic Algorithm for MultiObjective Optimization : NSGA-II. Lecture Notes in Computer Science 2000; 1917. DOI:https://doi.org/10. 1007/3-540-45356-3\_83.

28. Steinparzer F, Nefischer P, Hiemesch D et al. The New BMW Six-vylinder Top Engine with Innovative Turbocharging Concept. MTZ worldwide 2016; 77(10): 38-45. DOI:10.1016/j.rser.2014.08.079. 


\section{Figures}

Figure 1. Full load curve and studied points

Figure 2. Comparison between modelled and experimental GIE

Figure 3. Comparison between modelled and experimental $N O_{x}$ emissions

Figure 4. Methodology of optimization

Figure 5. Evolution of pressure and HRL at 1500_3 and 3500_19

Figure 6. HT effect on GIE in engine map

Figure 7. Evolution of optimum pressure and HRL at 3500_19 when different PRR limits are imposed

Figure 8. GIE variation respect to unconstrained optimum with HT when considering different PRR limits in engine $\operatorname{map}\left[\% \dot{m}_{f} H_{v}\right]$

Figure 9. Evolution of optimum pressure and HRL at 3500_19 when different PP limits are imposed

Figure 10. GIE variation respect to unconstrained optimum with HT when considering different PP limits in engine map $\left[\% \dot{m}_{f} H_{v}\right]$

Figure 11. Evolution of optimum pressure and HRL at 3500_19 when different PP and PRR limits are imposed

Figure 12. GIE variation respect to unconstrained optimum with HT when considering nominal pressure limits $\left(\mathrm{PRR}=10 \mathrm{bar} /{ }^{\circ}\right.$ and $\left.\mathrm{PP}=160 \mathrm{bar}\right)$ in engine map $\left[\% \dot{m}_{f} H_{v}\right]$

Figure 13. GIE in engine map when considering nominal pressure limits $\left(\mathrm{PRR}=10 \mathrm{bar} /{ }^{\circ}\right.$ and $\left.\mathrm{PP}=160 \mathrm{bar}\right)$

Figure 14. Evolution of gas mean temperature and combustion chamber walls temperature with and without coating at 1500_3

Figure 15. Effect of coating on GIE in engine map

Figure 16. Evolution of gas mean temperature and HRL at 3500_19 under different $N O_{x}$ emissions levels

Figure 17. Optimum tradeoff between GIE and $N O_{x}$ emissions at 3500_19 (top plot) and at all studied points (bottom plot)

Figure 18. GIE variation respect to nominal constrained optimum when decreasing $N O_{x}$ emissions up to $50 \%$ the experimental value in [\% $\left.\dot{m}_{f} H_{v}\right]$

Figure 19. Relative reduction respect to experimental $N O_{x}$ emissions value if experimental GIE is assumed in the theoretical optimization [\%] 


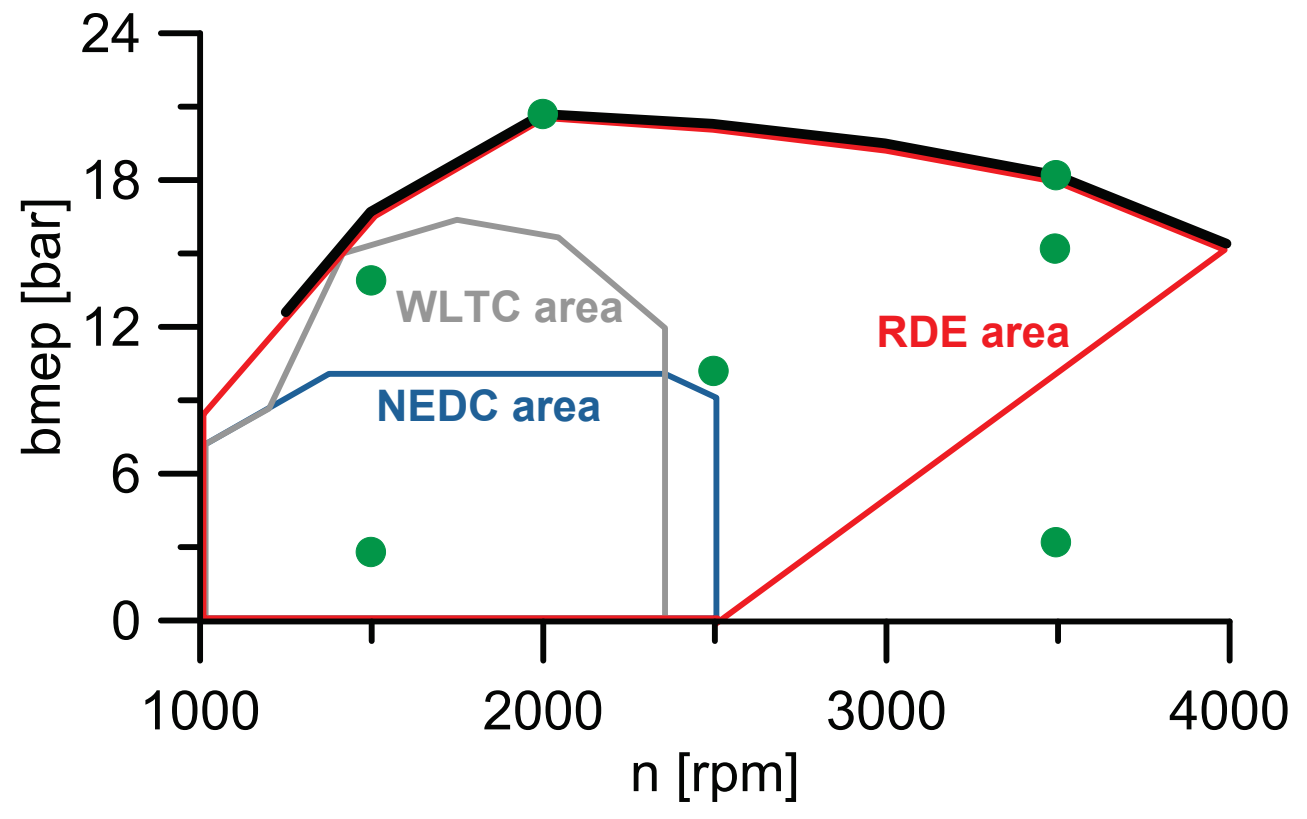

Figure 1. Full load curve, certification cycles areas and operating conditions included in the optimization 


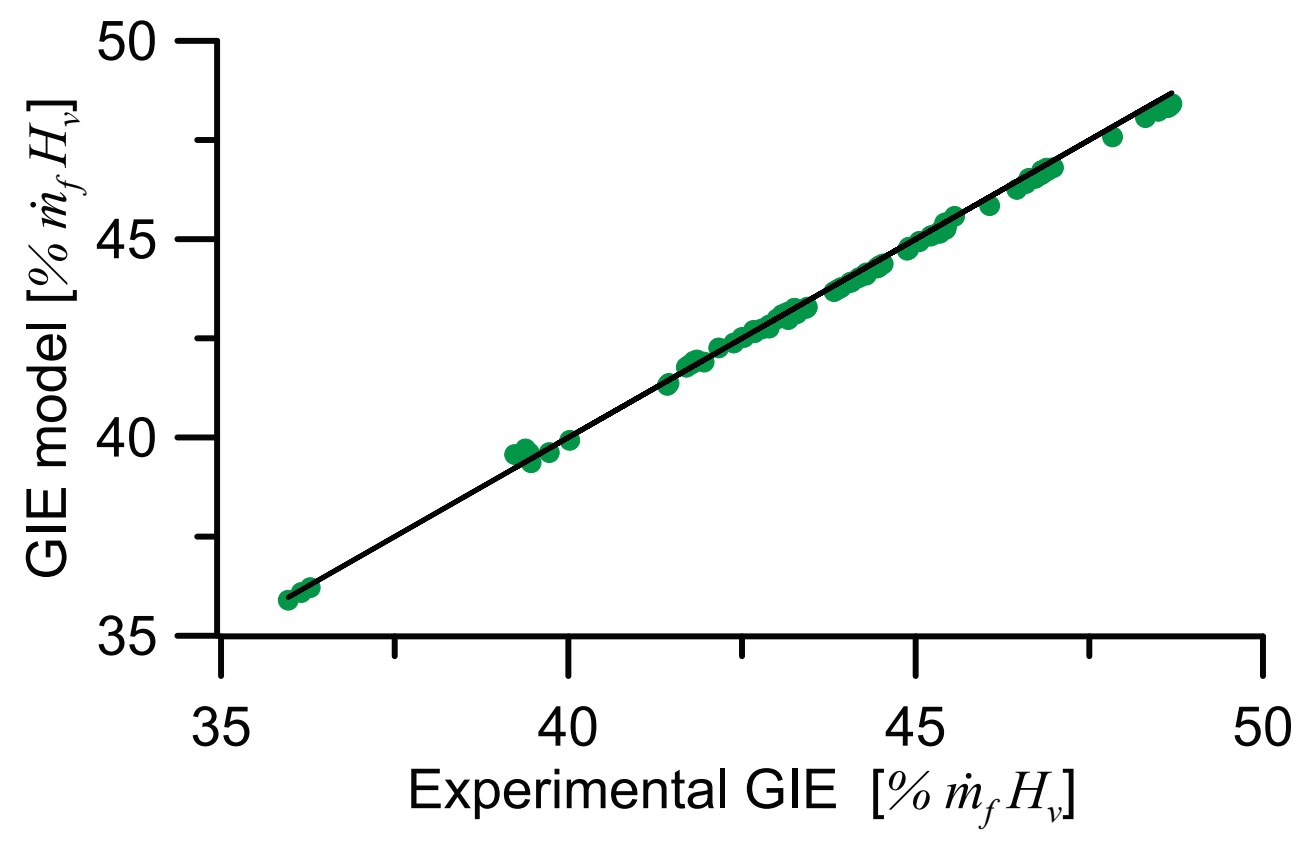

Figure 2. Comparison between modelled and experimental GIE 


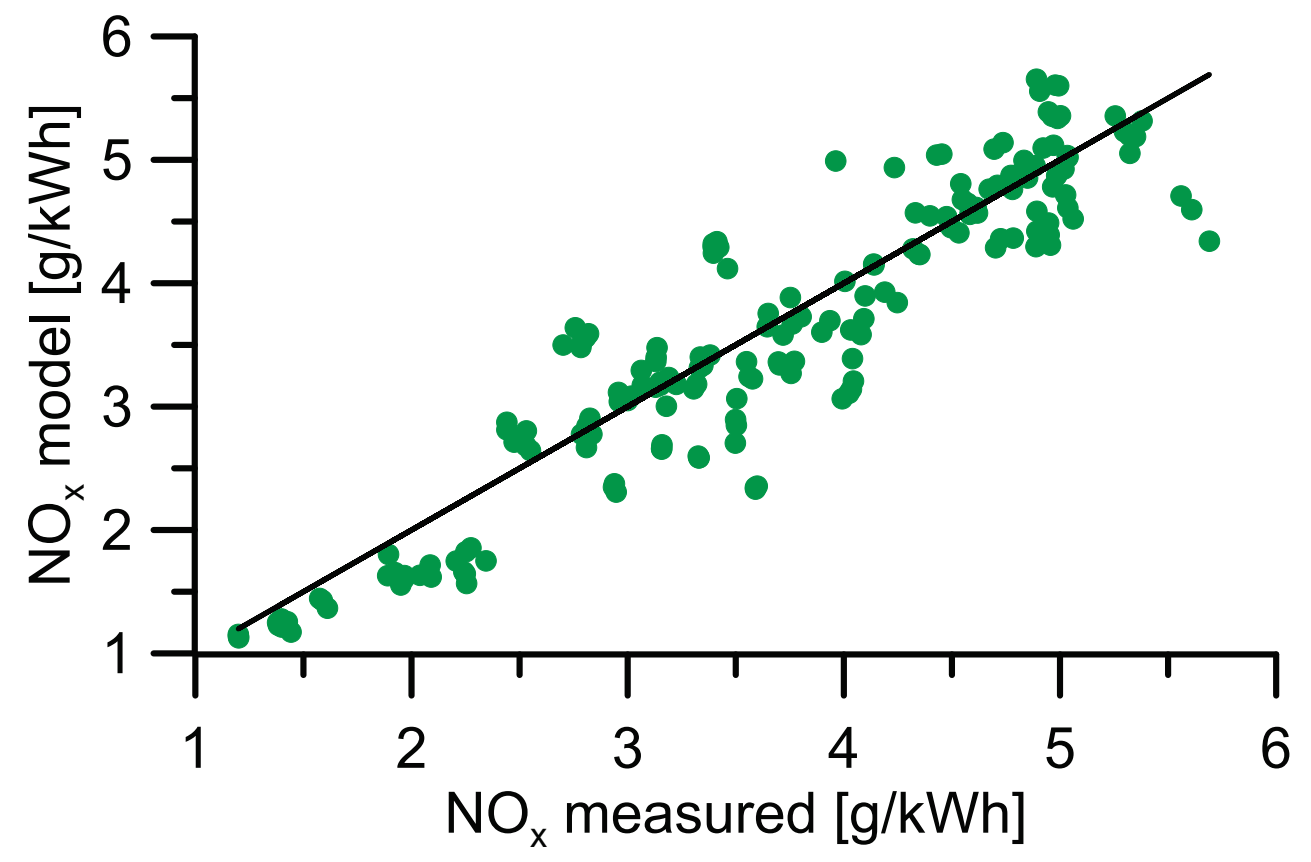

Figure 3. Comparison between modelled and experimental $N O_{x}$ emissions 


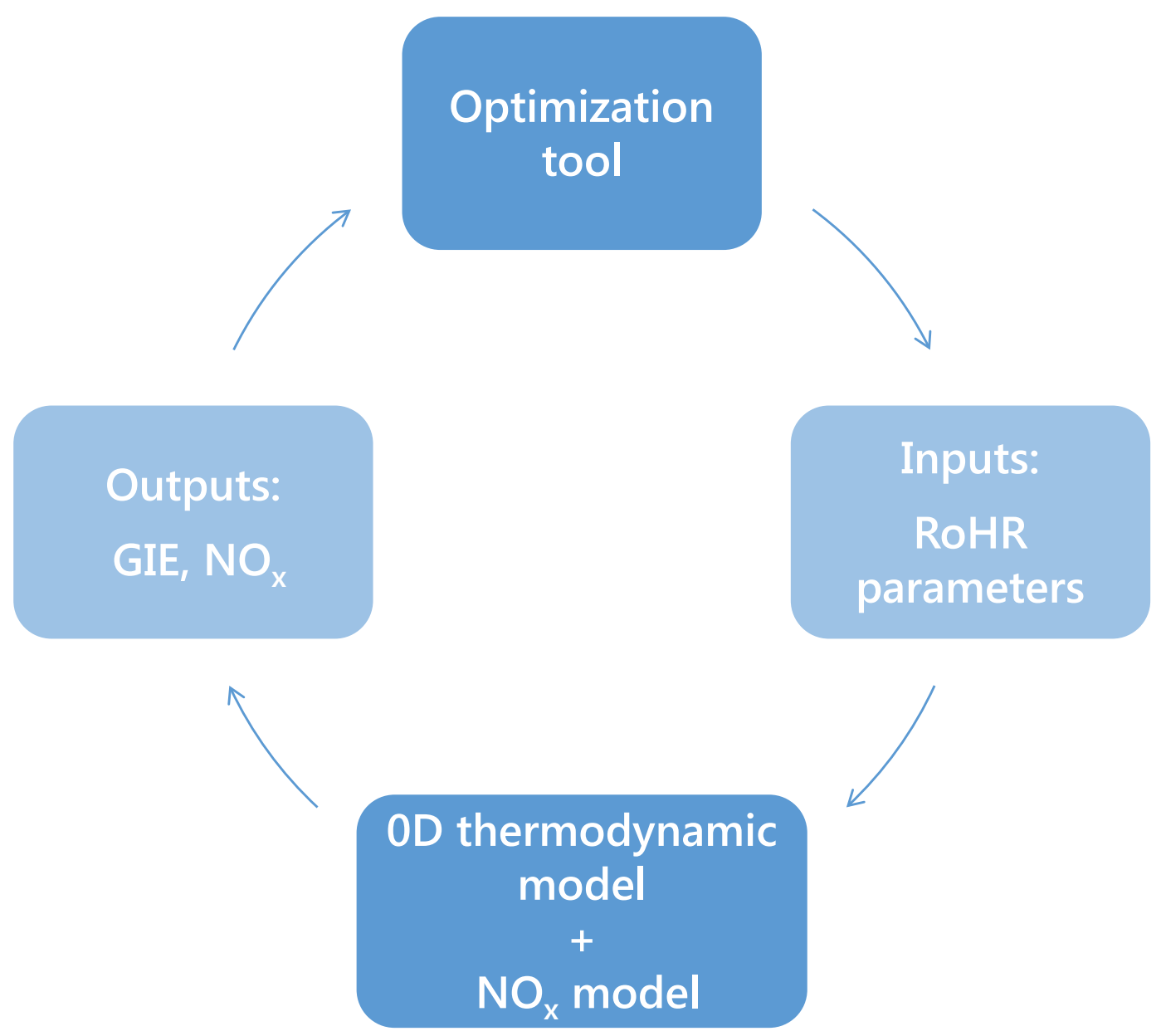

Figure 4. Methodology of optimization 

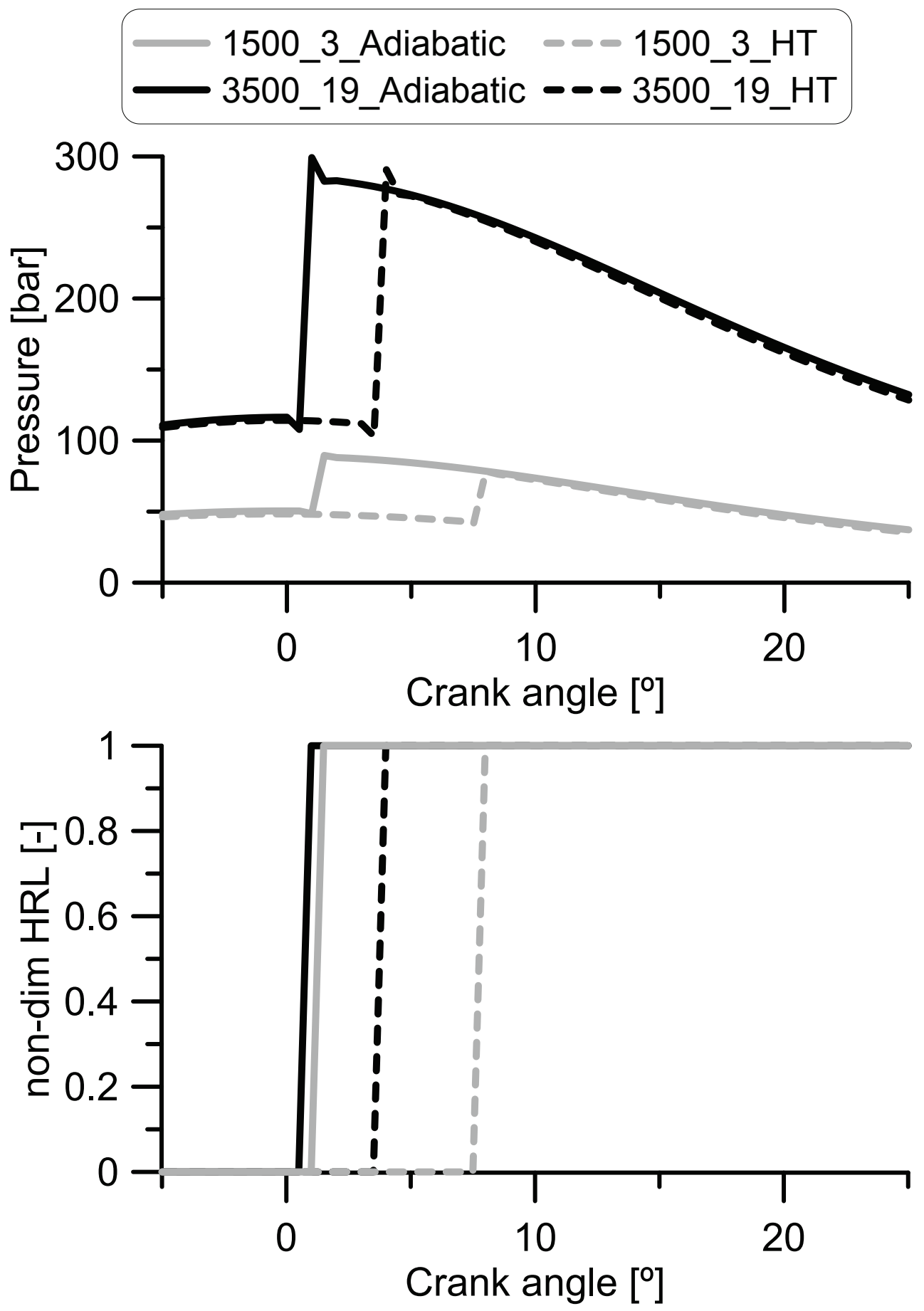

Figure 5. Evolution of pressure and HRL at 1500_3 and 3500_19 


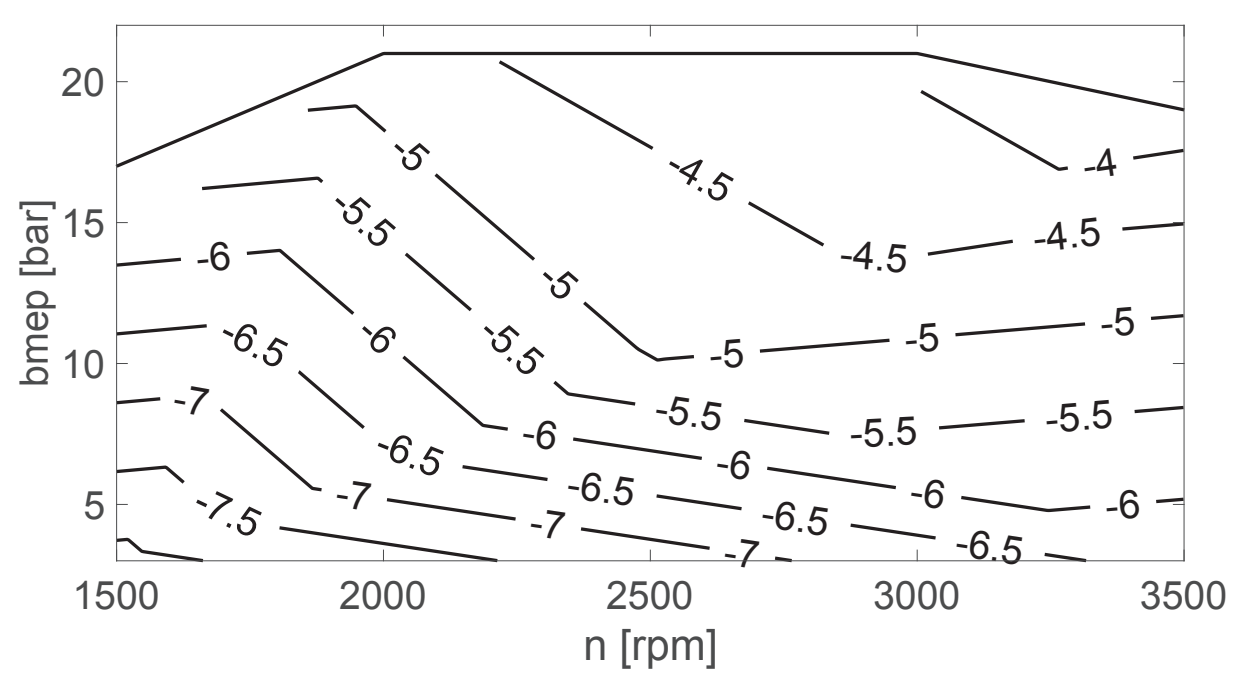

Figure 6. GIE variation respect to adiabatic unconstrained conditions when considering HT in engine map [\% $\dot{m}_{f} H_{v}$ ] 

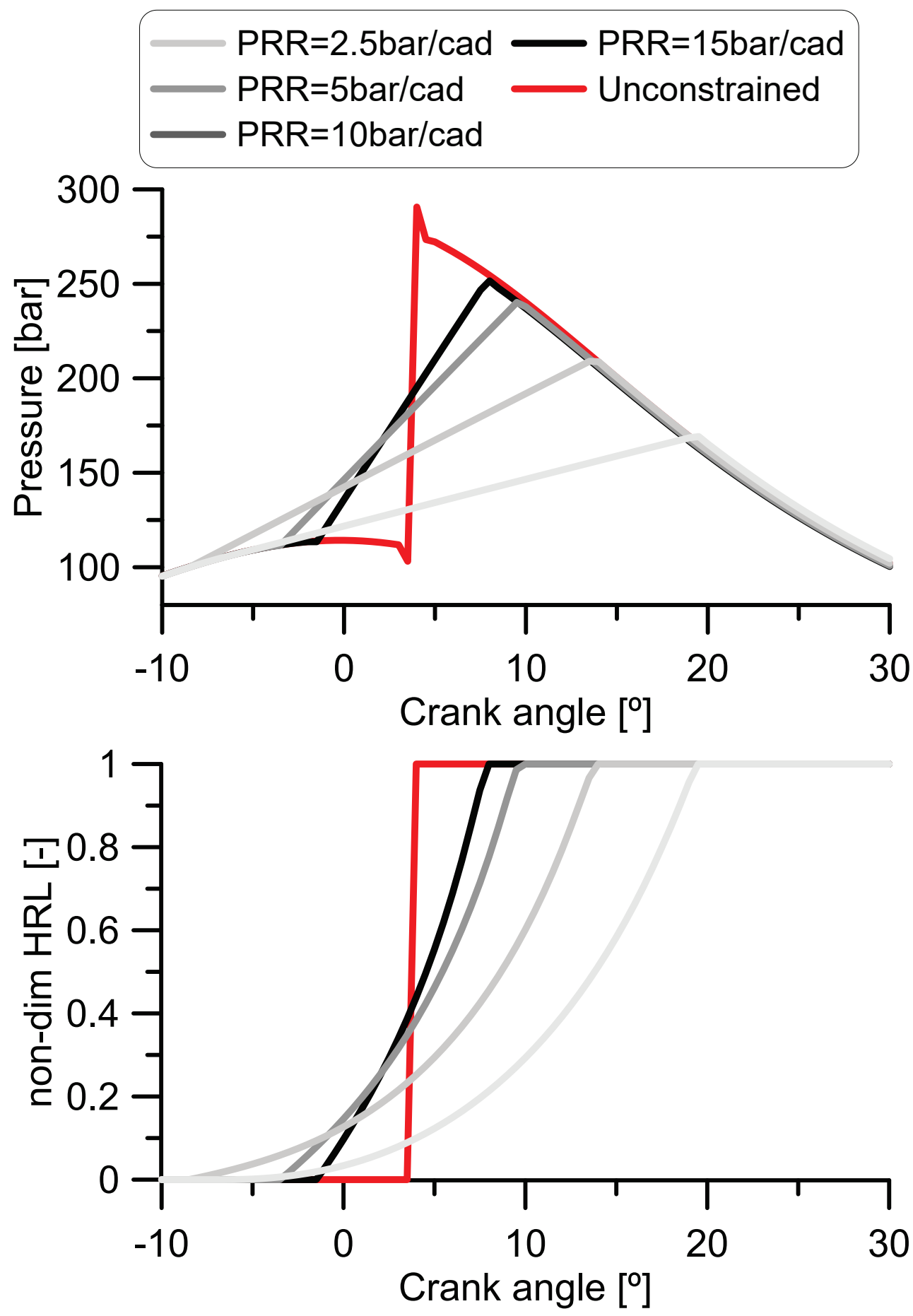

Figure 7. Evolution of optimum pressure and HRL at 3500_19 when different PRR limits are imposed 

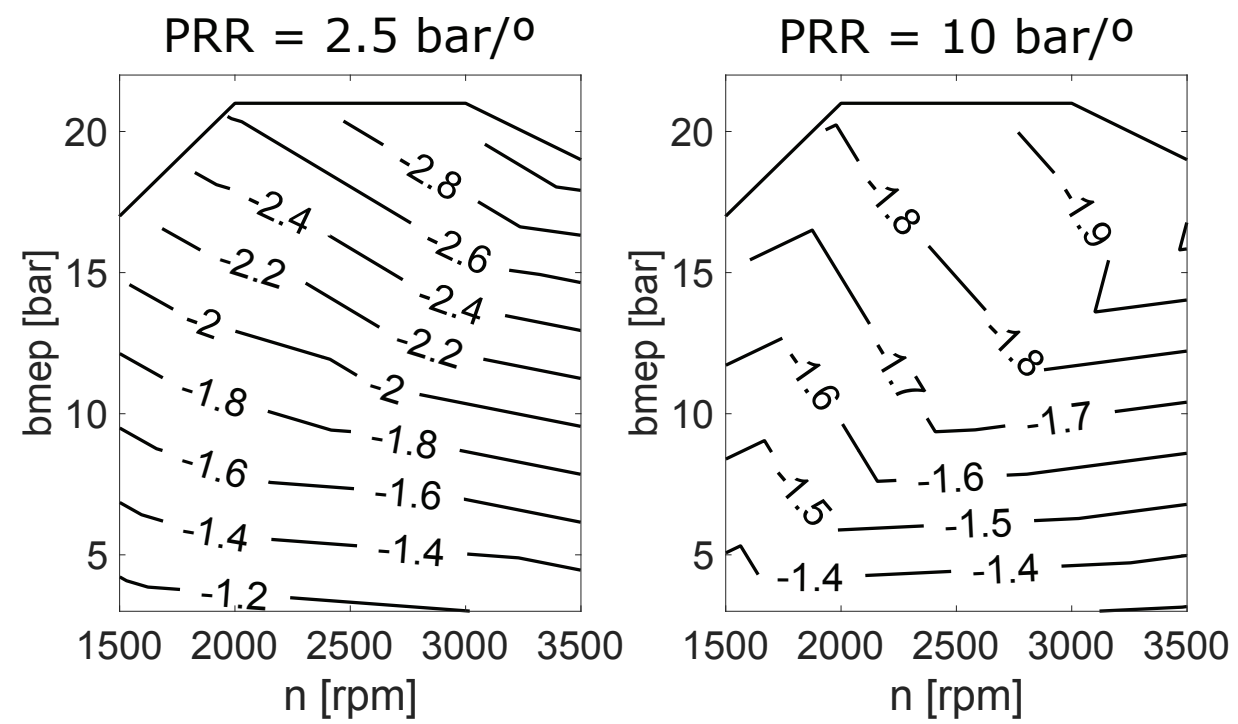

Figure 8. GIE variation respect to unconstrained optimum with HT when considering different PRR limits in engine map [\% $\dot{m}_{f} H_{v}$ ] 

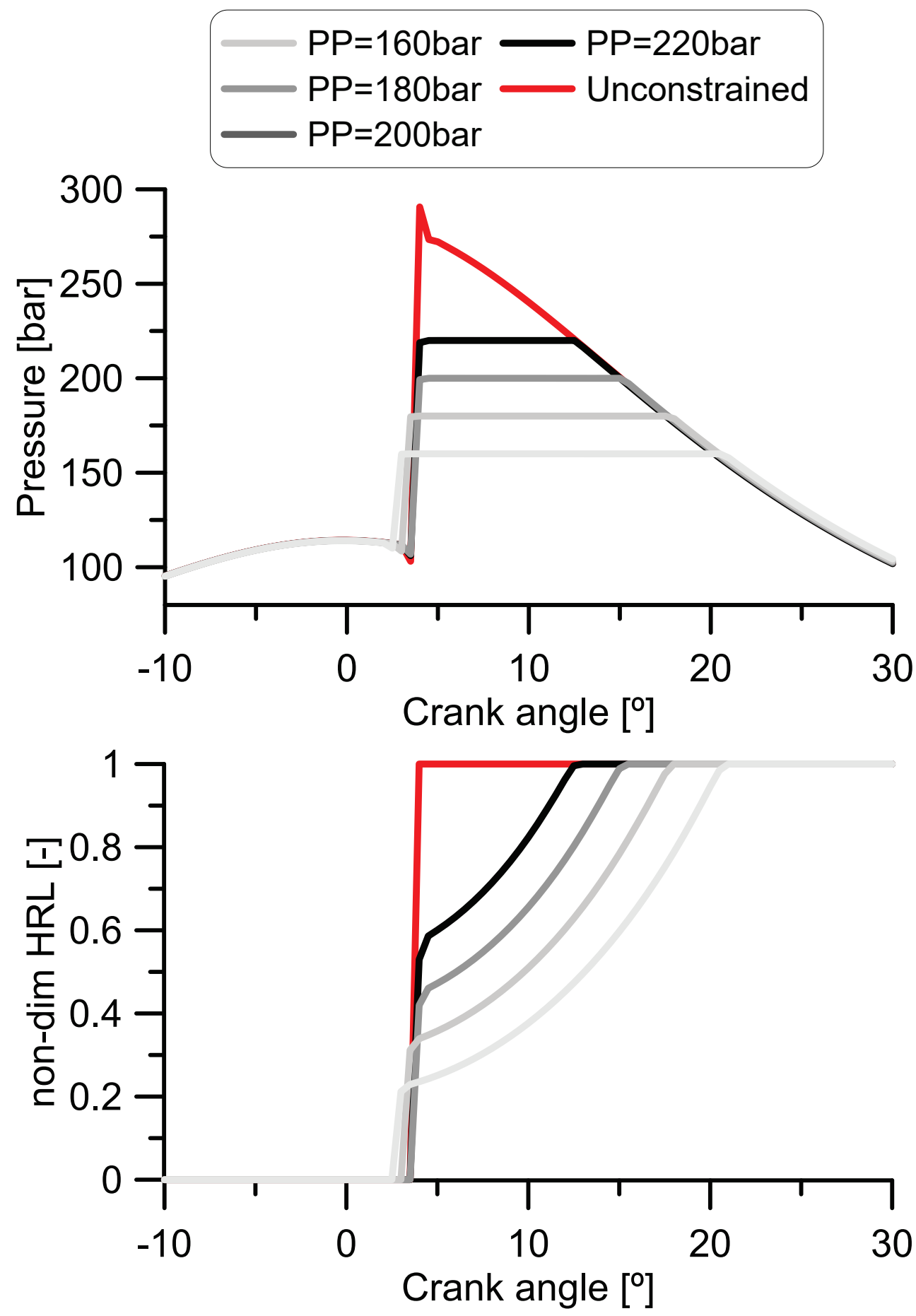

Figure 9. Evolution of optimum pressure and HRL at 3500_19 when different PP limits are imposed 

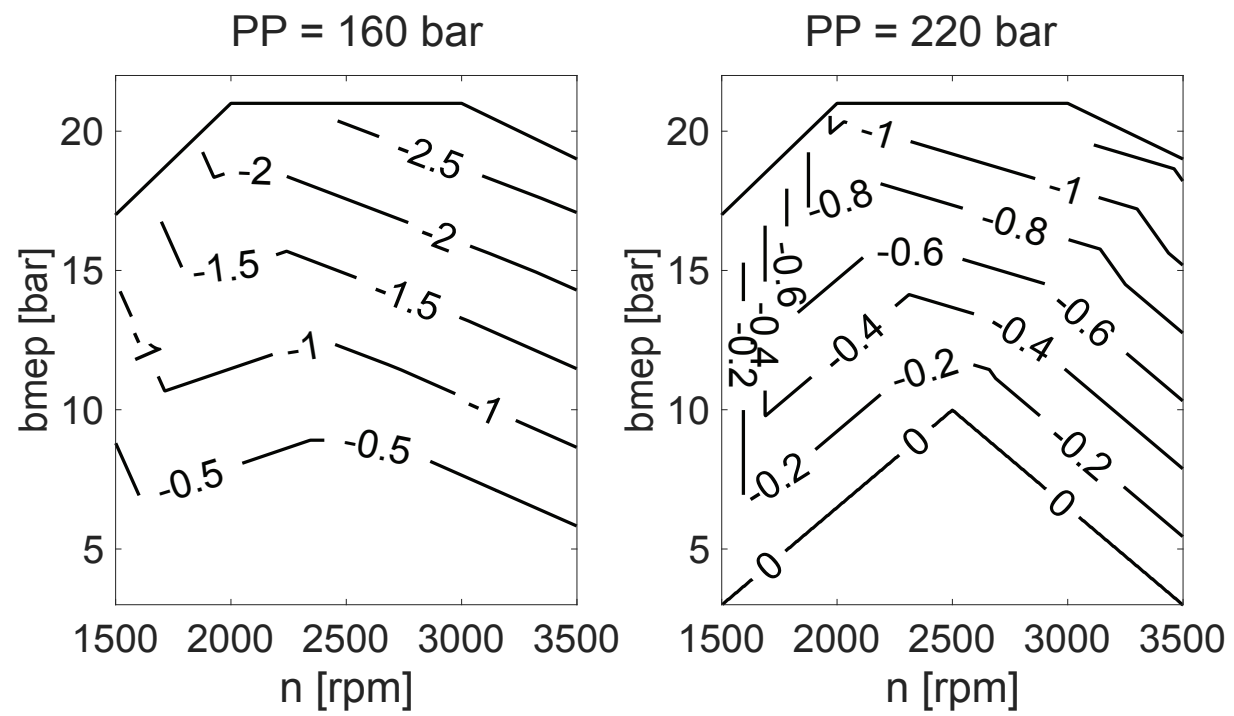

Figure 10. GIE variation respect to unconstrained optimum with $\mathrm{HT}$ when considering different PP limits in engine map [\% $\left.\dot{m}_{f} H_{v}\right]$ 

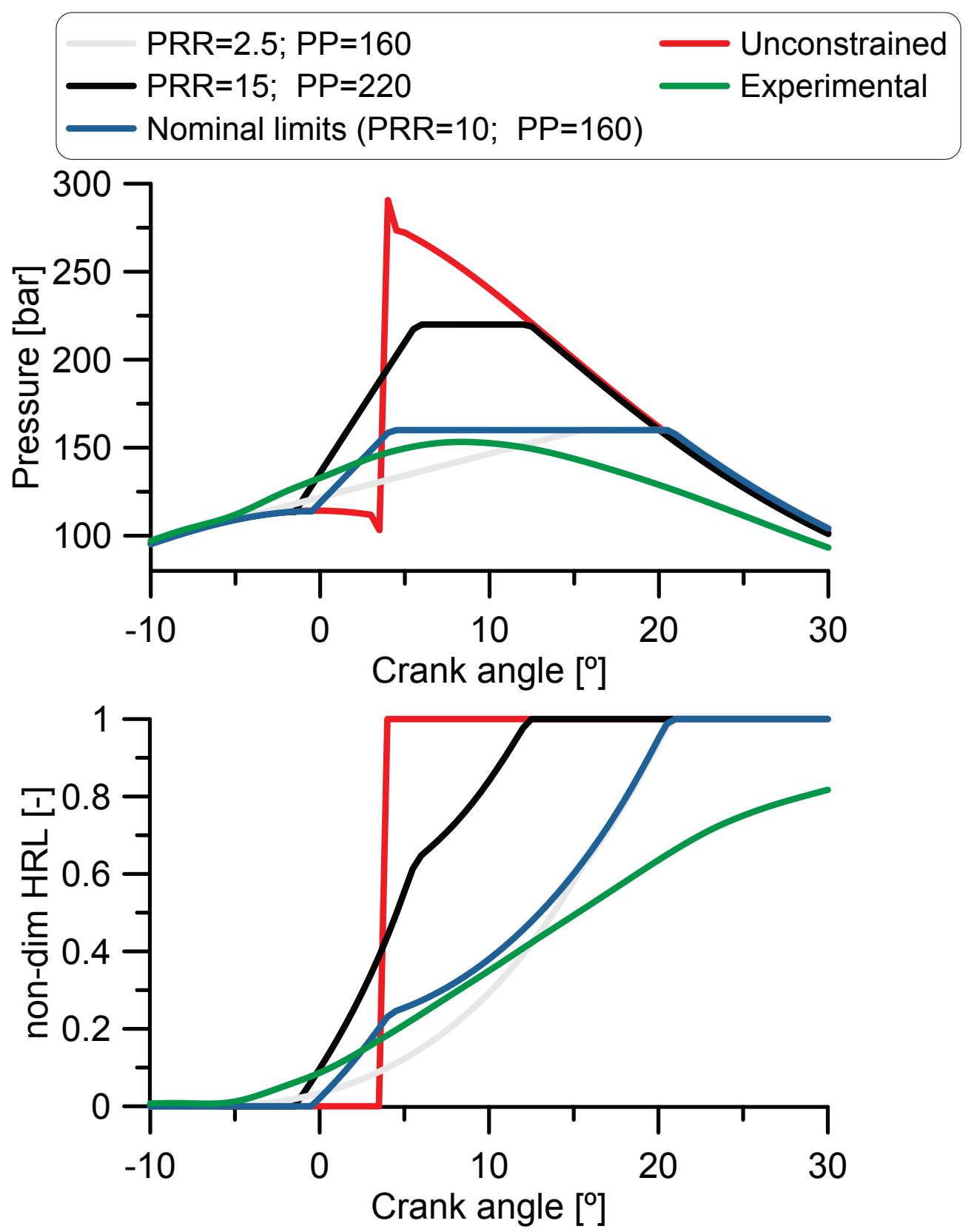

Figure 11. Evolution of optimum pressure and HRL at 3500_19 when different PP and PRR limits are imposed 


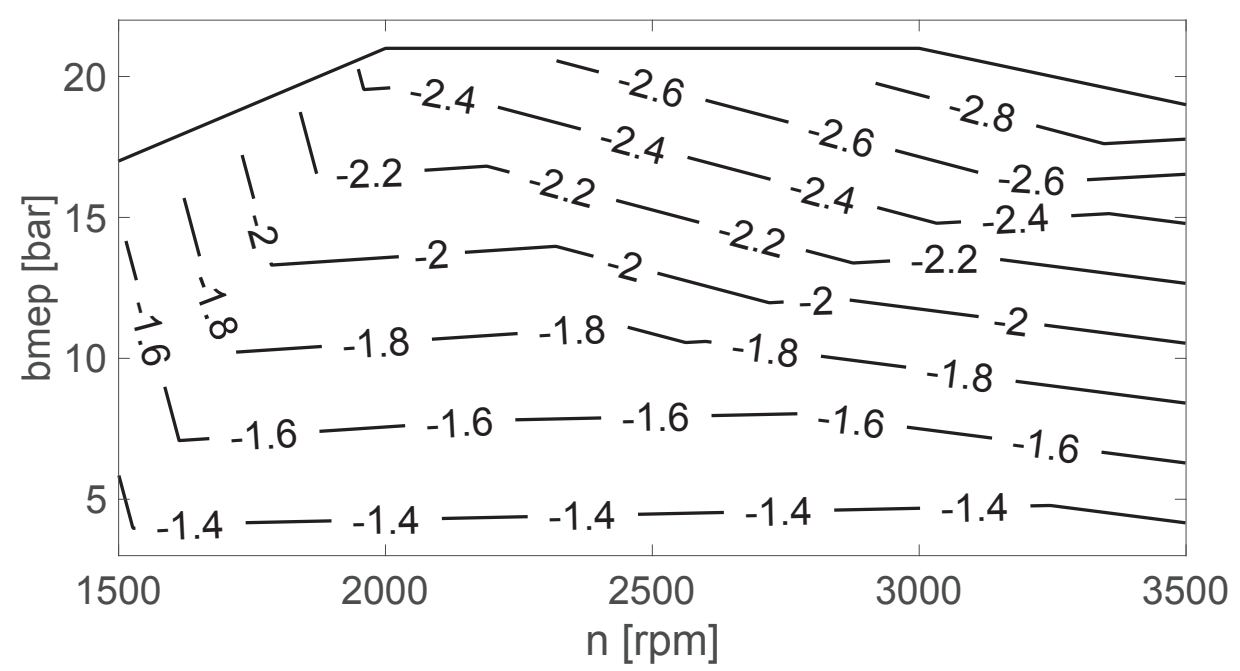

Figure 12. GIE variation respect to unconstrained optimum with $\mathrm{HT}$ when considering nominal pressure limits $\left(\mathrm{PRR}=10\right.$ bar $/{ }^{\circ}$ and $\mathrm{PP}=160$ bar) in engine map $\left[\% \dot{m}_{f} H_{v}\right]$ 


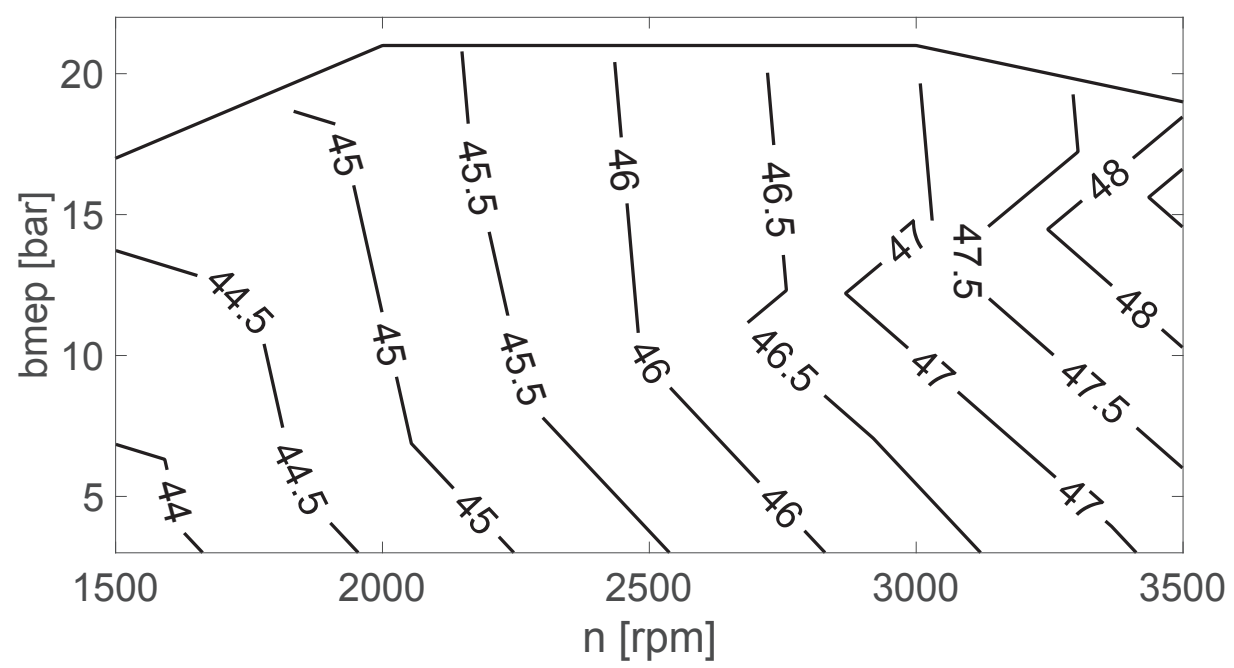

Figure 13. GIE in engine map when considering nominal pressure limits $\left(\mathrm{PRR}=10 \mathrm{bar} /{ }^{\circ}\right.$ and $\left.\mathrm{PP}=160 \mathrm{bar}\right)$ 


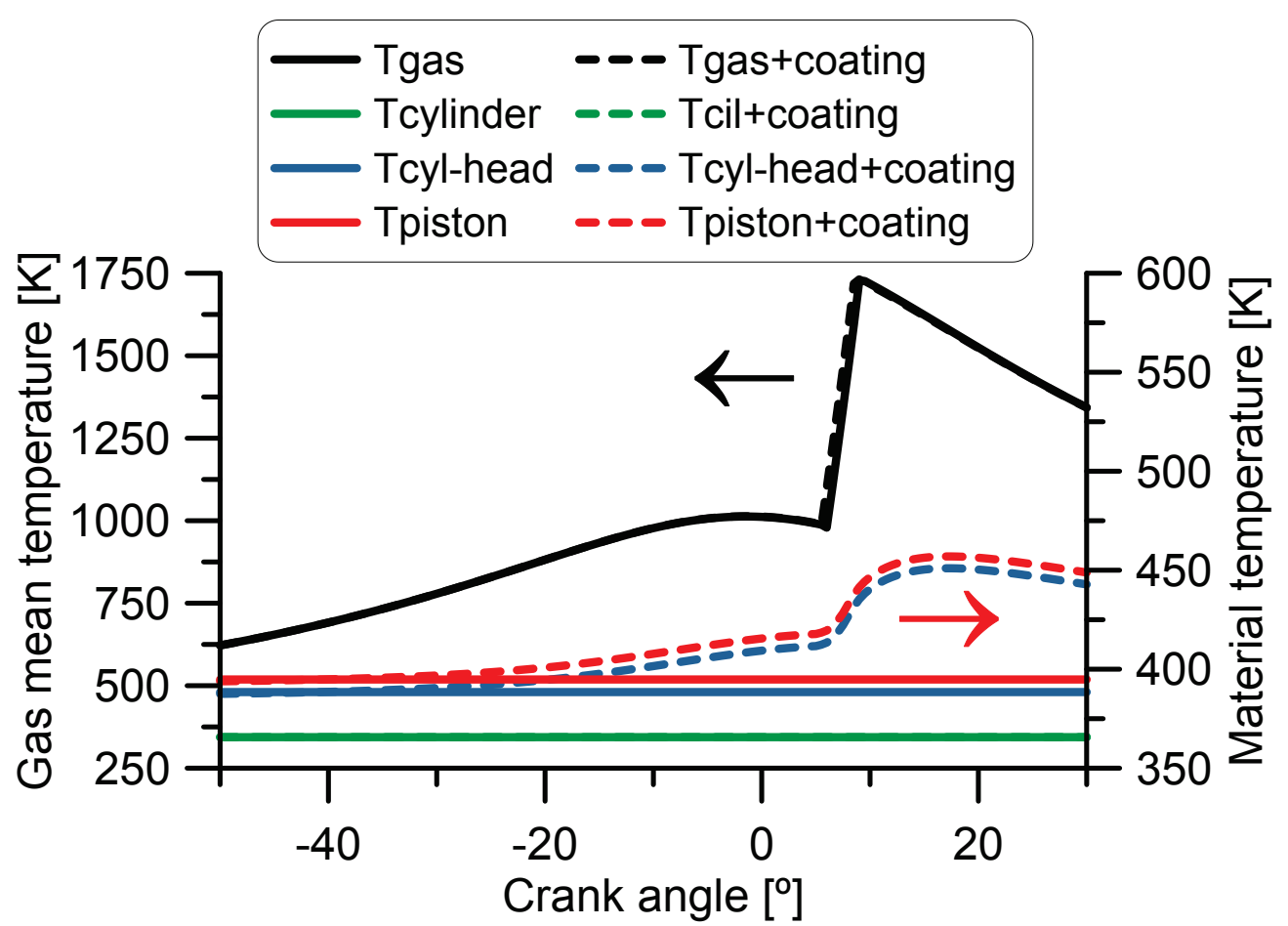

Figure 14. Evolution of gas mean temperature and combustion chamber walls temperature with and without coating at $1500 \_3$ 


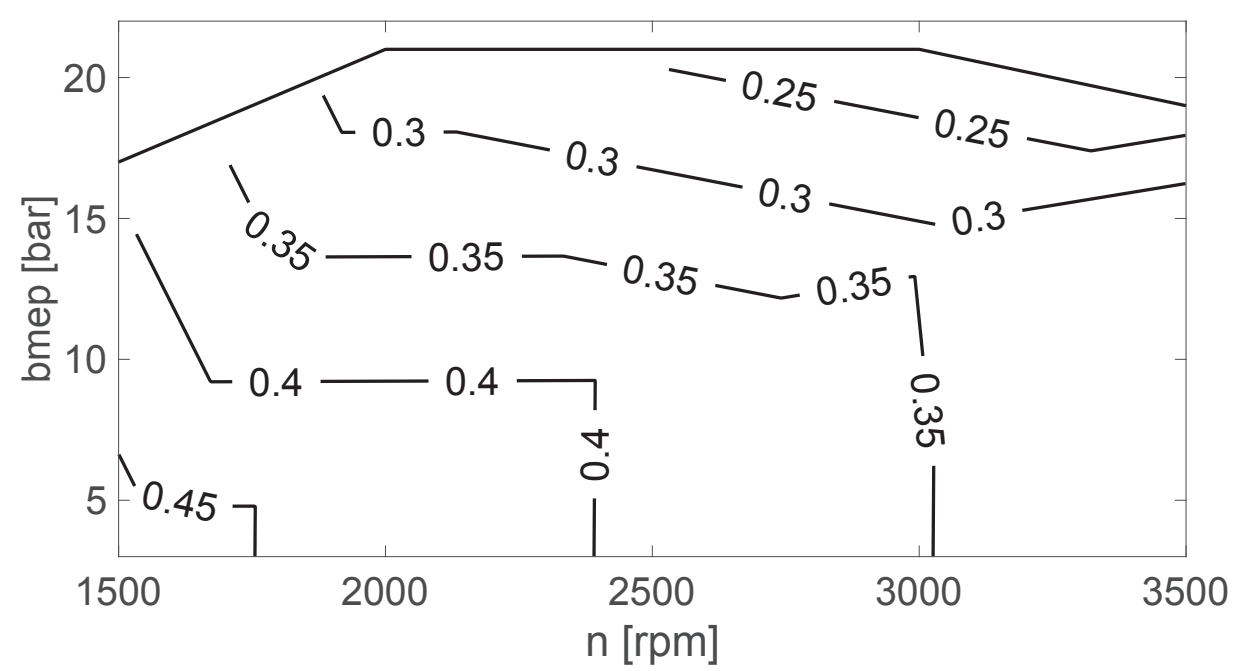

Figure 15. GIE variation respect to nominal constrained optimum due to the application of a temperature swing coating on cylinder-head and piston top surface [\% $\left.\dot{m}_{f} H_{v}\right]$ 

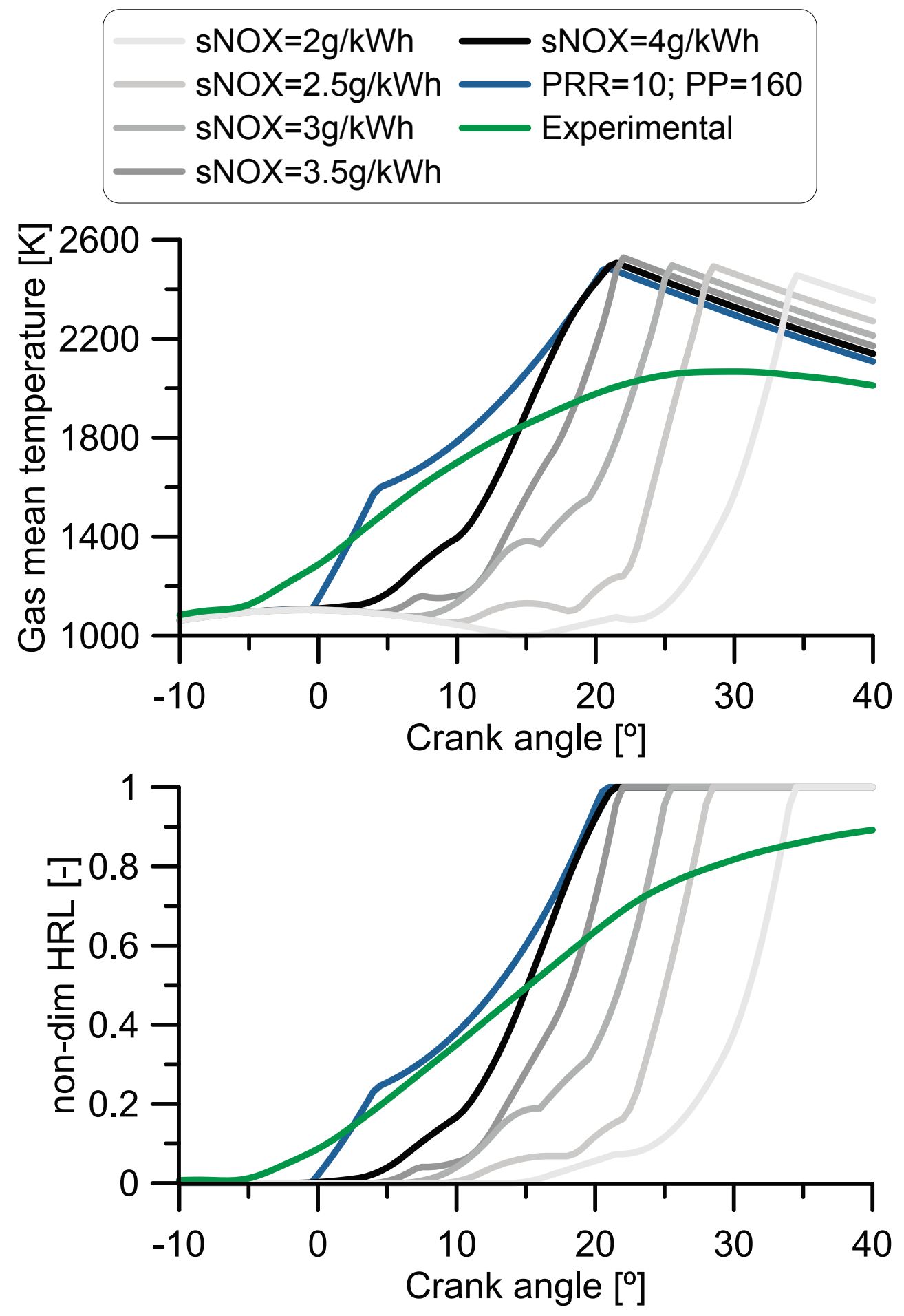

Figure 16. Evolution of gas mean temperature and $\mathrm{HRL}$ at 3500_19 under different $N O_{x}$ emissions levels 

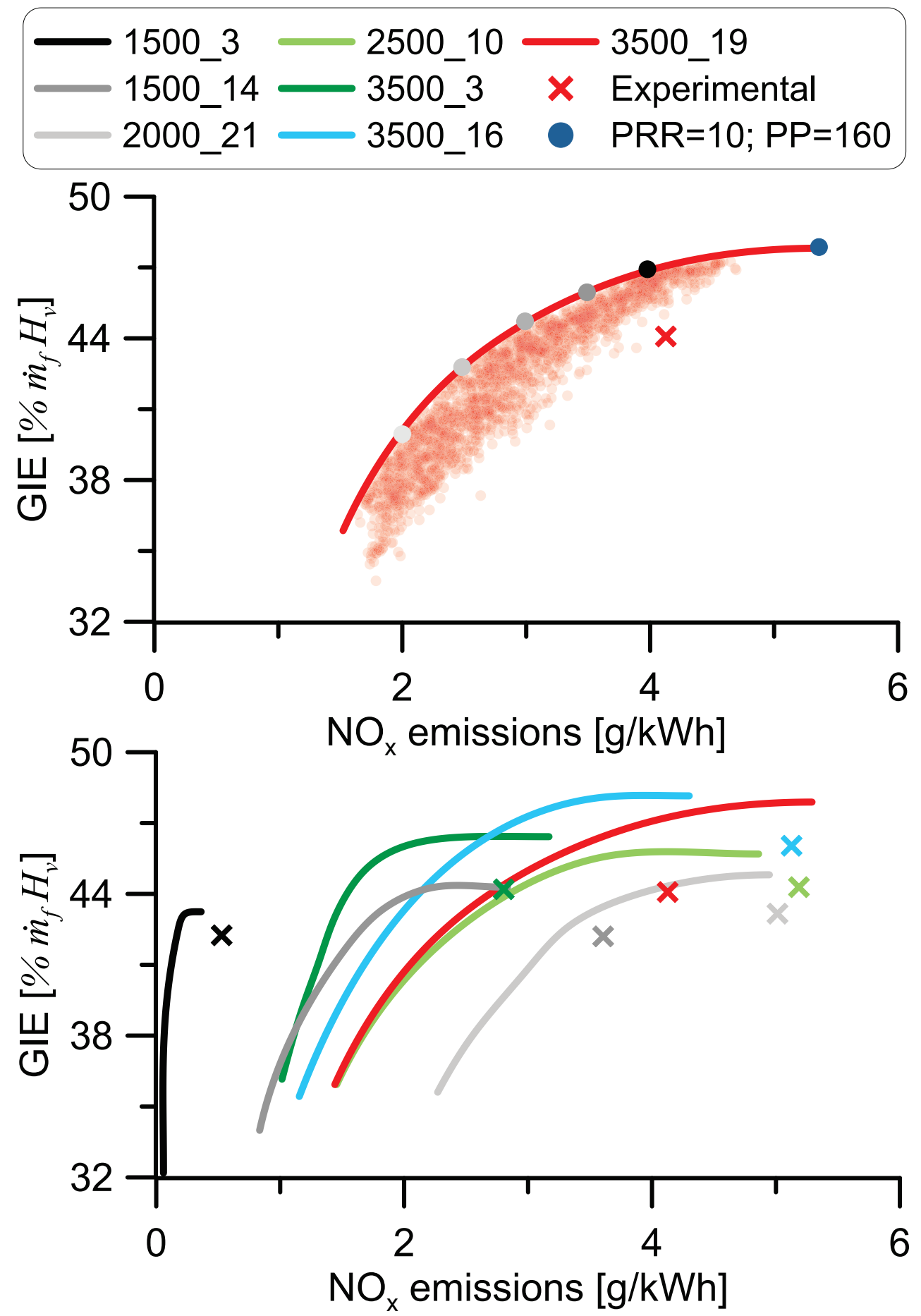

Figure 17. Optimum tradeoff between GIE and $N O_{x}$ emissions at 3500_19 (top plot) and at all studied points (bottom plot) 


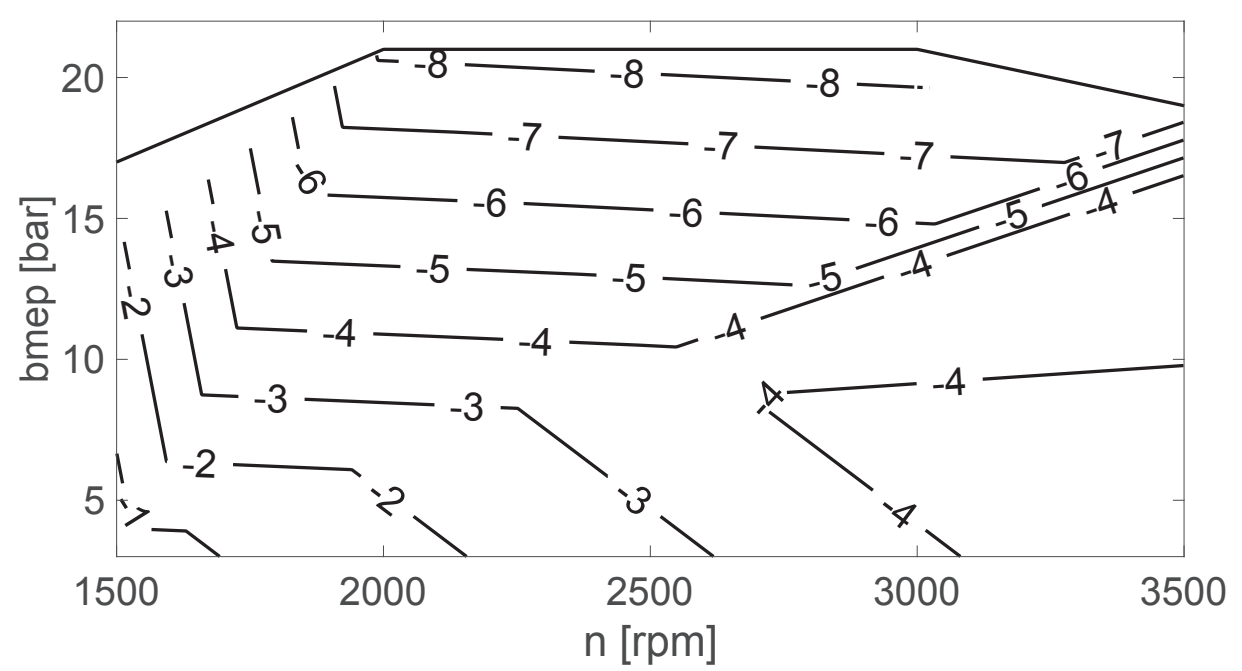

Figure 18. GIE variation respect to nominal constrained optimum when decreasing $N O_{x}$ emissions up to $50 \%$ the experimental value in $\left[\% \dot{m}_{f} H_{v}\right]$ 


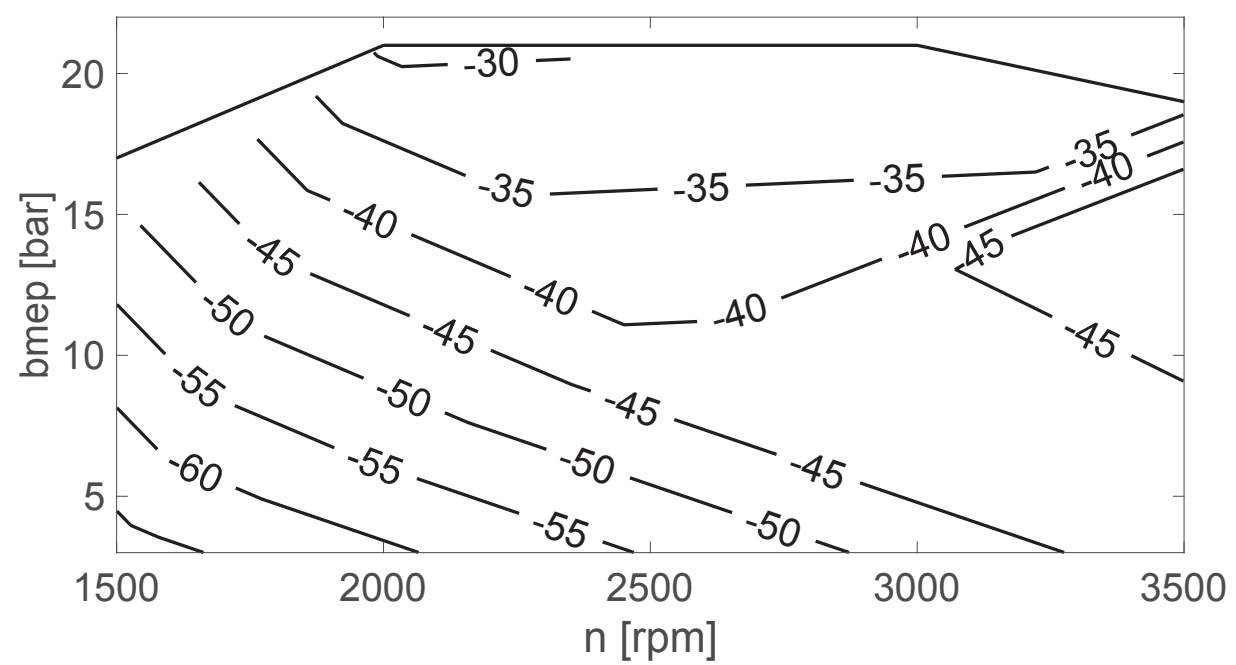

Figure 19. Relative reduction respect to experimental $N O_{x}$ emissions value if experimental GIE is assumed in the theoretical optimization [\%] 


\section{Tables}

Table 1. Engine technical data

Table 2. Measured operational k-points 


\begin{tabular}{ll}
\hline Cylinder & 4 in-line \\
Stroke & $90.4 \mathrm{~mm}$ \\
Bore & $82 \mathrm{~mm}$ \\
Geometric CR & $17.5: 1$ \\
Number of valves/cylinder & 4 \\
Air Management & Turbocharged \\
Maximum power & $110 \mathrm{~kW} @ 4000 \mathrm{rpm}$ \\
Maximum torque & $315 \mathrm{Nm} @ 2000 \mathrm{rpm}$ \\
Cycle & Diesel \\
Injection & Common rail \\
Swirl ratio & $1.4-3$ \\
\hline
\end{tabular}

Table 1. Engine technical data 


\begin{tabular}{lc|ccccccc}
$\begin{array}{l}\text { Engine speed } \\
{[\mathrm{rpm}]}\end{array}$ & $\begin{array}{c}\text { BMEP } \\
{[\mathrm{bar}]}\end{array}$ & $\begin{array}{c}\text { Boost pressure } \\
{[\mathrm{bar}]}\end{array}$ & $\begin{array}{c}\text { Intake T } \\
{\left[{ }^{\circ} \mathrm{C}\right]}\end{array}$ & $\begin{array}{c}\text { EGR } \\
{[\%]}\end{array}$ & $\begin{array}{c}\text { Rail pressure } \\
{[\mathrm{bar}]}\end{array}$ & $\begin{array}{c}\text { Fuel mass } \\
{[\mathrm{mg} / \mathrm{cc}]}\end{array}$ & $\begin{array}{c}\text { GIE } \\
{[\%]}\end{array}$ & $\begin{array}{c}s N O_{x} \\
{[\mathrm{~g} / \mathrm{kWh}]}\end{array}$ \\
\hline 1500 & 2.8 & 1.08 & 45 & 35 & 390 & 10.4 & 42.25 & 0.53 \\
1500 & 13.9 & 1.75 & 45 & 3 & 1040 & 45.7 & 42.20 & 3.61 \\
2000 & 20.7 & 2.18 & 47 & 0 & 1240 & 59.7 & 43.29 & 5.01 \\
2500 & 10.2 & 1.85 & 46 & 0 & 1240 & 29.1 & 44.29 & 5.18 \\
3500 & 3.2 & 1.58 & 45 & 0 & 910 & 13.5 & 44.20 & 2.8 \\
3500 & 15.2 & 2.33 & 45 & 0 & 1590 & 43.9 & 46.04 & 5.13 \\
3500 & 18.2 & 2.37 & 45 & 0 & 1600 & 54.2 & 44.08 & 4.13 \\
\hline
\end{tabular}

Table 2. Experimental data set 